OPEN ACCESS

Edited by:

Francois Vandenesch, Université de Lyon, France

Reviewed by: Jerome Lemoine,

Université de Lyon, France Karsten Becker,

University Medicine

Greifswald, Germany

*Correspondence: Antti Vasala antti.i.vasala@gmail.com

Specialty section:

This article was submitted to

Clinical Microbiology,

a section of the journal

Frontiers in Cellular and Infection

Microbiology

Received: 17 January 2020 Accepted: 22 May 2020

Published: 15 July 2020

Citation:

Vasala A, Hytönen VP and Laitinen $\mathrm{OH}$ (2020) Modern Tools for Rapid

Diagnostics of Antimicrobial Resistance.

Front. Cell. Infect. Microbiol. 10:308. doi: 10.3389/fcimb.2020.00308

\section{Modern Tools for Rapid Diagnostics of Antimicrobial Resistance}

\author{
Antti Vasala ${ }^{1 *}$, Vesa P. Hytönen ${ }^{1,2}$ and Olli H. Laitinen ${ }^{1}$ \\ ${ }^{1}$ Protein Dynamics, Faculty of Medicine and Health Technology, Tampere University, Tampere, Finland, ${ }^{2}$ Fimlab Laboratories, \\ Tampere, Finland
}

Fast, robust, and affordable antimicrobial susceptibility testing (AST) is required, as roughly $50 \%$ of antibiotic treatments are started with wrong antibiotics and without a proper diagnosis of the pathogen. Validated growth-based AST according to EUCAST or CLSI (European Committee on Antimicrobial Susceptibility Testing, Clinical Laboratory Standards Institute) recommendations is currently suggested to guide the antimicrobial therapy. Any new AST should be validated against these standard methods. Many rapid diagnostic techniques can already provide pathogen identification. Some of them can additionally detect the presence of resistance genes or resistance proteins, but usually isolated pure cultures are needed for AST. We discuss the value of the technologies applying nucleic acid amplification, whole genome sequencing, and hybridization as well as immunodiagnostic and mass spectrometry-based methods and biosensor-based AST. Additionally, we evaluate the potential of integrated systems applying microfluidics to integrate cultivation, lysis, purification, and signal reading steps. We discuss technologies and commercial products with potential for Point-of-Care Testing (POCT) and their capability to analyze polymicrobial samples without pre-purification steps. The purpose of this critical review is to present the needs and drivers for AST development, to show the benefits and limitations of AST methods, to introduce promising new POCT-compatible technologies, and to discuss AST technologies that are likely to thrive in the future.

\footnotetext{
Keywords: antibiotic resistance, antimicrobial susceptibility test, antimicrobial resistance, point of care test, rapid AST
}

\section{BACKGROUND AND FOREWORD}

There is an unmet need for rapid and decentralized diagnostics in outpatient clinics to reduce the misuse of antibiotics. It is important to identify the etiological pathogen and to differentiate between viral and bacterial infections, to identify the antimicrobial resistances in microbes, and to find out which antimicrobial agent should be used for the cure. Thereby the unnecessary use of antibiotics could be minimized and the spread of antibiotic resistance better controlled. According to the WHO, antimicrobial resistance (AMR) is the largest global health threat in the 21 st century and requires urgent measures. Common infections are becoming untreatable due to the emergence of AMR. More than 700,000 people die of drug-resistant infections every year, and this figure is expected to reach ten million by 2050 (United nations meeting on antimicrobial resistance, 2016). According to current understanding, in EU and EEA countries more than 33000 people are killed every year due to antibiotic-resistant bacteria. They also cause close to 900000 disability-adjusted years (Cassini et al., 2019). Bringing diagnostics closer to the general practitioners and hence to the patient would cause a paradigm shift from empirical to 
evidence-based treatments of infectious diseases in outpatient clinics. Rapid diagnostics are needed for both pathogen identification and resistance testing. The prevalence of AMR may be very high for some species in certain geographic locations. According to the current recommendations on AST (antimicrobial susceptibility testing), pure culture isolates are used to test the effect of antimicrobial drugs. This is required as the sample matrix (blood, urine, mucosal) as well as the number and proportions of different microbial species may vary a lot in polymicrobial samples. It may be unclear whether the detected microbe is pathogenic or merely a commensal species. Despite significant progress in diagnostic technologies in recent years, most patients with infectious diseases are still treated empirically and thus antibiotics are heavily overused (Li et al., 2016; Mashalla et al., 2017). Even in Western countries, $30 \%$ of antibiotic prescriptions are considered to be either unnecessary or suboptimal (Centers for Disease Control Prevention, 2018). Current diagnostic tests serve hospitalized patients rather well, but they are often not available in outpatient clinics. For typical growth-based AST, several cultivation rounds are required: enrichment cultivations (e.g., blood cultures) to increase the number of bacteria, plate cultivations to obtain pure cultures, and finally AST for liquid or plate cultures using various antimicrobial loads. Microbiology laboratories apply the EUCAST-accepted breakpoint values to define whether the microbe is susceptible or resistant to the tested antibiotic. They use the disk diffusion method or other systems calibrated to EUCAST standards. Altogether, AST may require several days. Rapid molecular diagnostics has been discussed in many excellent reviews (Pulido et al., 2013; Plüddemann et al., 2015; Li et al., 2017b; Maurer et al., 2017; Syal et al., 2017; Maugeri et al., 2019). They present the progress in Nucleic Acid Amplification Technology (NAAT), electrochemical methods, microarrays, micro- and nanoparticles, as well as mass spectrometry applications, but also emphasize that very few of the molecular methods have acquired FDA approval.

The review of David Boyle, "Tuberculosis Diagnostics Technology Landscape" is worth reading, since, although not focusing on AST, it presents comprehensively new affordable molecular diagnostic technologies available in standard microscopy stations, particularly in developing countries (Boyle, 2017). The most up-to-date and concise progress compendia in the field of AST can be found in congress presentations, lectures and webinars. Prof. Mark Fisher's webinar "Rapid Antimicrobial Susceptibility Testing" (ARUP, 2020; Scientific

\footnotetext{
Abbreviations: AMR, Antimicrobial Resistance; AR gene, Antibiotic Resistance gene; AST, Antimicrobial susceptibility testing; CLSI, Clinical \& Laboratory Standards Institute; EUCAST, European Committee on Antimicrobial Susceptibility Testing; CFU, Colony forming units; FISH, Fluorescence in situ Hybridization; ID, Identification; LF, Lateral flow; LCR, Ligase Chain Reaction; MALDI-TOF, Matrix-Assisted Laser Desorption/Ionization TimeOf-Flight mass spectrometry; MIC, Minimal Inhibitory Concentration; POCT, Point of Care Testing; NA= Nucleic Acid; NAAT, Nucleic Acid Amplification Technology; PIT, Plasmonic Imaging and Tracking; SERS, Surface Enhanced Raman Scattering; FEED, field effect enzymatic detection; MADM, Multiplexed Automated Digital Microscopy; PNA, Peptide-Nucleic Acid probe; WGS, Whole Genome Sequencing.
}

Resource for Research and Education: Educational ResourcesRapid Antimicrobial Susceptibility Testing | University of Utah) is particularly useful.

The innovations in electronics, biosensor techniques, optics, microfluidics, hybridization technologies and DNA amplification technologies have yielded new approaches in AST. Unfortunately, the scientific papers on these technologies do not sufficiently relate these findings to the practical needs in POCT. The requirement of a microbiology laboratory and the time and resources needed for the enrichment of cultures, preparation of pure cultures. and sample treatments is often not sufficiently considered. These requirements also easily blur the total costs of AST. For these reasons, the deployment of new molecular methods for AST has been very slow (Doern, 2018). The standards of care for antibiotic prescription are quite consistent in most European countries and the USA and apply evidence-based ID and AST when available. In total, urinary and respiratory tract infections form a significant part of acute infections. Quick and accurate diagnosis for these diseases already at outpatient settings could efficiently restrict the spread of AMR bacteria and allow an early isolation of the carrier and correct treatment. Rapid diagnosis would also allow the prompt dismantling of unnecessary patient isolation, saving money and resources. However, technical improvements translate into benefits only if the structured communication and interpretation of the results are applied by the clinicians (Maurer et al., 2017) and the cost of these technologies are reasonable.

Vital emergency diagnostics for septicaemia has received a lot of resources (Marco, 2017; Hughes, 2018). New sensitive methods such as T2MR (T2Biosystems, USA) can quickly detect molecular targets directly from clinical samples, enabling rapid pathogen identification and detection of resistance factors. However, growth-based AST for blood requires a fairly high bacterial count for enrichment cultures and a well-equipped microbiology laboratory. The achievements in blood testing do not necessarily relate well to the antimicrobial stewardship in the front-line: healthcare settings.

Optimal antimicrobial therapy policy would require (1) Fast point of care analysis, (2) Identification of the etiological agent, (3) Finding of an efficient antibiotic, and (4) Determination of the functional dosage. According to Prof. Gunnar Kahlmeter (Chairman, EUCAST general committee) (Kahlmeter, 2016), the key questions for any new AST technology are:

- Is it generally applicable or suitable only for one infection (for example sepsis or one resistance type)?

- What is the capacity? How many organisms/agents per hour can be processed?

- Has the technology been validated against reference methods?

- Are there any reference installations?

- Is scientific literature available?

- When will it be on the market?

Complete answers are hard to dig up, but this review tries to address these questions. We present the needs and drivers for AST development, increase the understanding about the role of rapid AST in diagnostics of infectious diseases, show the benefits and limitations of AST methods, introduce the key 
POCT-compatible technologies, and contemplate on which AST technologies are likely to thrive in the future.

\section{CURRENT TECHNOLOGIES IN ANTIMICROBIAL SUSCEPTIBILITY TESTING AND MICROBIAL IDENTIFICATION}

Bacteria can acquire resistance to antibiotics by several mechanisms. The antibiotic can be degraded or chemically modified (by acetylation, phosphorylation, nucleotidylation, ADP-ribosylation, mono-oxygenation, glycosylation). The drug intake can be prevented, or efflux can be enhanced. Some resistance mechanisms are based on the reprogramming of cell wall synthesis. Even slight changes in the target molecule, e.g., a point mutation in the ribosomal protein, can render the antibiotic inefficient. The overwhelming variety of antimicrobials and resistance mechanisms complicates AST. Genotypic (nucleic acid-based) methods can only find resistances that are searched for, and the potentially found resistance genes are not necessarily from the actual pathogenic organism. According to EUCAST and CLSI guidelines, reliable antibiotic resistance diagnostics requires phenotypic testing, i.e., an experimental test whether the microorganism grows in the presence of the antibiotic. These methods work regardless of the resistance mechanism and give answers to the practical questions: which antibiotic is efficient and which dose should be applied in the therapy. Classical AST techniques such as broth microdilution, disk diffusion, gradient tests, agar dilution and breakpoint tests are based on continuous exposure of a bacterial isolate to a set of antimicrobials, followed by a visual detection of growth. The use of advanced optoelectronic systems, fiber optics, microfluidics and indicator dyes sensitive to redox-state or $\mathrm{pH}$ can further enhance the sensitivity and performance of optical systems.

Several commercial systems have streamlined and partly automatized the follow-up of AST cultures. Systems like Vitek and Microscan perform automated turbidity measurement for multiwell liquid cultures. BD Phoenix system ${ }^{\mathrm{TM}}$ applies a redox indicator to enhance the detection of organism growth. These systems have turnaround times as short as $4 \mathrm{~h}$ for ID and 6-8 $\mathrm{h}$ for susceptibility testing (She and Bender, 2019). The CE-marked Alfed $60 \mathrm{AST}^{\mathrm{TM}}$ system (Alifax, Italy) uses sensitive laser-light scattering technology to detect bacterial growth in a liquid culture broth and provides antimicrobial susceptibility results directly from positive blood culture bottles within 4-6 h.

Such broth dilution-based systems use ready-made AST cassettes or cards containing positive controls and wells with increasing concentrations of antibiotics. They provide continuous growth monitoring and can analyze MIC patterns for a large group of organisms through their extensive databases.

Pathogen identification (ID) is usually a preliminary step of AST. For blood samples, microscopy and Gram-staining are nearly always performed, as Gram-positive bacteria in general have a more limited variety of antibiotic resistances and less problems with multidrug resistance. In AST, the following sequence is typically applied: First clinical samples are cultured to obtain pure isolates. Then identification (with MALDI-TOF mass spectrometer, if available) is performed. Thereafter, AST and MIC determination is performed according to EUCAST or CLSI standards. This sequence, in total, requires several days. Standard healthcare settings do not have advanced microbiology laboratories with mass spectrometry instruments. Their arsenal for the diagnosis of infectious diseases may be limited to immuno-chromatographic strip tests (aka lateral flow tests $=\mathrm{LF}$ or "dip-sticks") applied to the detection of viruses (e.g., influenza) and bacterial pathogens causing sexually transmitted diseases.

Quick identification can efficiently restrict the search palette for certain antibiotics. Hence mass spectrometry has become a versatile workhorse in clinical laboratories. It is routinely applied for bacterial ID as soon as isolated colonies are available. Through the simultaneous measurement of several metabolites a biochemical signature of microbes can be obtained. Matrixassisted laser desorption/ionization time of flight (MALDI-TOF) applies laser energy to evaporate the matrix-bound sample, that is then immediately analyzed. When frequent sampling is applied, MALDI-TOF can even provide semi-quantitative growth rate data (Maxson et al., 2017). Bruker Corp. (Germany) has launched test kits such as BT STAR-Carba Assay for AST based on antibiotic degradation monitoring.

AST for blood cultures has been applied after a short-term cultivation on agar plates followed by susceptibility testing using VITEK AST cards selected on the basis of MALDITOF analysis (Idelevich et al., 2014; Mauri et al., 2017). By applying the MBT-ASTRA ${ }^{\mathrm{TM}}$ test with MALDI Biotyper for ID and AST, identification of mycobacterial strains resistant to rifampicin, isoniazid, linezolid, ethambutol, clarithromycin and rifabutin can be obtained 1 week faster than through routine cultivation-based AST (Ceyssens et al., 2017). The MS approaches combined with NAAT or microfluidics will be presented in "Future technologies" section.

\section{CURRENT TECHNOLOGIES FOR RAPID AST}

Many novel methods claim to perform AST in minutes or in few hours. Such statements usually ignore the need of timeconsuming steps such as enrichment cultures and isolation of pure cultures (Figure 1). Methods based on NAAT, nucleic acid hybridization or immunodiagnostics in principle allow the use of non-purified polymicrobial clinical samples. A short cultivation with a pre-determined antibiotic load followed by NAAT (e.g., isothermal amplification) can reveal AR, and even provide a rough estimate of the minimal inhibitory concentration (MIC) for the tested antibiotics. Most rapid growth-based AST methods perform end-point analysis only, whilst others rely on frequent sampling from the cultivation chamber. Some sensitive immunodiagnostic systems however provide real on-line growth monitoring (Figure 2). Biosensor technologies detecting changes in microbial metabolism, movement or heat production have not yet provided convincing clinical demonstrations. Fast, reliable, easy-to-use and inexpensive systems applicable to AST in outpatient clinics are still elusive (van Belkum et al., 2019a). 


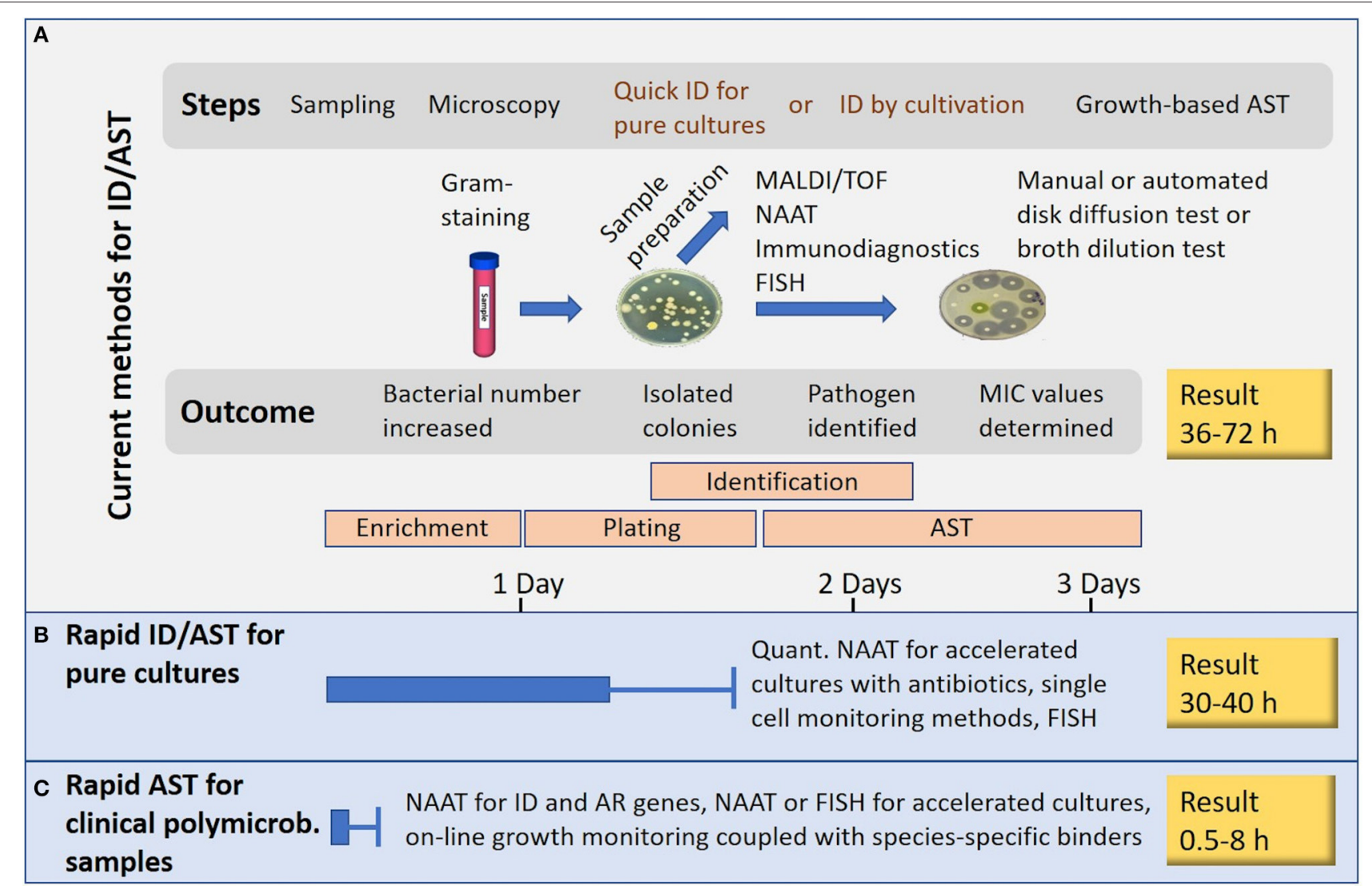

FIGURE 1 | Rapid AST or rapid result? (A) Current technologies. (B) Rapid AST applicable to pure cultures. (C) Rapid AST for clinical polymicrobial samples. The presented times are rough estimates and generalizations.

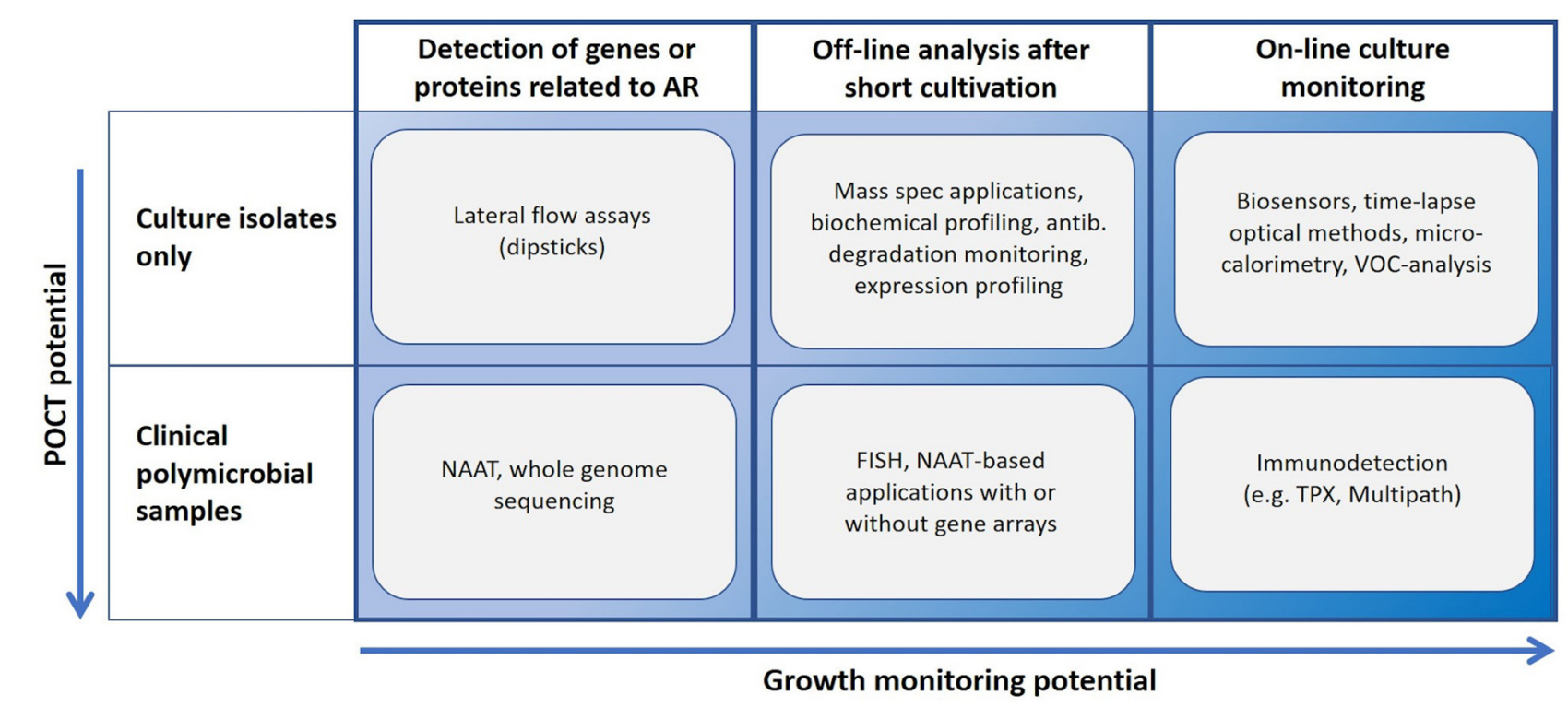

FIGURE 2 | Usability landscape of rapid AST technologies. NAAT, nucleic acid amplification technology; TPX, immunodetection based on two-photon excitation fluorometry; Multipath, immunodiagnostic method applying magnetic spheres for cell separation, fluorescent nanoparticles for labeling and non-microscopic imaging. 


\section{Microscopy}

Counting of bacteria on agar plates by microscopy techniques is possible long before they have reached the number providing visible colonies. E. coli colonies visible by eye contain roughly $5 \times 10^{6}$ bacteria, but by microscopy microcolonies formed by 120 cells can already be detected (London et al., 2010). Drug susceptibility (MODS) for Mycobacterium tuberculosis can be assessed by observing cell aggregates (cords) microscopically in sealed microtiter plates (den Hertog et al., 2014). The Growth Direct System by Rapid Micro Biosystems Inc. detects microcolonies with digital imaging by illuminating them with blue light and directing the cellular autofluorescence directly onto a CCD chip without magnification. The average time for $E$. coli detection by this autofluorescence was $3.1 \mathrm{~h}$ compared to an average of $8.5 \mathrm{~h}$ for the visual plate counting method. Although the idea of applying this to AST has been declared in the patent application, clinical studies for AST have not yet been presented.

Automated microscopy systems can provide real time growth curves, and quantitative bacterial counts have been presented. Multiplexed automated digital microscopy (MADM) applying Fluorescent in situ Hybridization (FISH) has been commercialized by Accelerated Diagnostics (USA) for rapid online AST (Metzger et al., 2014; Chantell, 2015). The Accelerate Pheno ${ }^{\circledR}$ system can separate impurities from clinical samples (e.g., blood or urine) by brief electrophoresis, which runs impurities into a gel. After this a change of the electric field polarity repels the microbes back to the liquid. A fluorescence signal is detected every $10 \mathrm{~min}$ from samples taken from the bacterial culture multiplying in Mueller-Hinton media (CharnotKatsikas et al., 2017). This system seems to be currently the only FDA-approved growth-based rapid diagnostic AST system (Doern, 2018). The performance of Accelerate Pheno ${ }^{\circledR}$ has been demonstrated with many clinical studies, e.g., with urinary tract infections (Charnot-Katsikas et al., 2017) and bloodstream infections (Charnot-Katsikas et al., 2017; Marschal et al., 2017; Descours et al., 2018). With 232 positive blood cultures tested, the overall essential agreement with routine methods was $95.1 \%$, and the time needed for AST was decreased by $42 \mathrm{~h}$ in comparison to standard growth-based analysis. ID could be obtained in $1.5 \mathrm{~h}$ and AST in $7 \mathrm{~h}$ (Charnot-Katsikas et al., 2017).

\section{Hybridization-Based Systems}

FISH is a highly specific method to visualize the presence of the target organism in a quantitative manner. The PNA-FISH technology applies peptide nucleic acid probes which allow more rapid and specific binding than DNA or RNA probes (PerryO'Keefe et al., 2001; Almeida et al., 2009; Cerqueira et al., 2011). It is applied in the commercial QuickFish technology (OpGen, USA) which performs ID by targeting 16S rRNA (Enroth et al., 2019). XpressFish specifically detects the mecA gene in Staphylococcus, allowing, when used subsequent to QuickFishbased identification, diagnosis of methicillin resistance already $2 \mathrm{~h}$ after the blood culture turns positive (Salimnia et al., 2014). Since a temperature of $55^{\circ} \mathrm{C}$ is needed for target cell permeabilization, fixing and hybridization, PNA-FISH systems are not applicable to on-line growth monitoring. FDA-approved systems are available also from bioMérieux (Durham, NC).
Clinical laboratories applying mass spectrometry are unlikely to need PNA-FISH technology; the Bruker MALDI Septityper ${ }^{\circledR}$ kit PBP2A, e.g., can detect the mecA-encoded PBP2A-protein in $1 \mathrm{~h}$ with fairly low costs.

In actively growing cells, RNA is more abundant than DNA and thus a good target for probing. Especially precursor rRNA (pre-rRNA), the intermediate stage in the formation of mature rRNA, is a good indicator of bacterial metabolism, viability, and growth rate (Halford et al., 2013). The biosensorbased AST (b-AST) system from Genefluidics Inc. (CA, USA) measures bacterial growth by quantifying 16s rRNA molecules with an electrochemical biosensor. This system uses speciesspecific probes and integrates nanotechnology, plastic micro electromechanical system and microfluidics (Mach et al., 2011). This system achieved a detection limit of $10^{4} \mathrm{cfu} \mathrm{ml}^{-1}$ in rapid AST of clinical urine and blood samples (Liu et al., 2014). Mohan et al. demonstrated the simultaneous detection of uropathogens and the host biomarker lactoferrin in urinary tract infection, but reached only $89 \%$ sensitivity in the pathogen identification (Mohan et al., 2011). In 2018 Genefluidics announced CE-IVD Marking for the UtiMax ${ }^{\mathrm{TM}}$ kit, which provides ID in $30 \mathrm{~min}$ and AST in $2 \mathrm{~h}$ from urine with an overall sensitivity of $100 \%$ and specificity of $98.2 \%$ (GeneFludics Inc., n.d.).

\section{Nucleic Acid Amplification Technology (NAAT) in AST}

The first generation "molecular tests" such as restriction fragment length polymorphism, pulsed-field electrophoresis, multiple locus tandem repeat analysis, multi-locus sequence typing and virulence genotyping were suitable rather for typing and outbreak investigation than for AST. Since these technologies require a high amount of purified nucleic acid, they do not allow rapid diagnostics. However, hybridization-based approaches and molecular beacon systems have persisted and are creatively combined with NAAT technologies.

NAAT is a very powerful tool for pathogen identification, especially when combined with a syndromic approach. Many diagnostic panels provided e.g., by BioMérieux, Elitech, Bosch, Eplex, Qiagen, or Becton Dickinson, include detection of specific AR-genes. They can provide clinically relevant results, especially in cases where a detailed antibiogram is not needed. For example, pathogen such as Bordetella, Legionella, Mycoplasma, Chlamydia trachomatis, or Neisseria gonorrhea exhibit quite few antibiotic resistances. The detection of specific AR genes, however, cannot give an undisputed proof of antibiotic resistance. The identified AR genes do not necessarily relate to the pathogen causing the disease, or the found resistance gene may not be functional. NAAT neither defines the MICs nor directly indicates which antibiotics should be used. An advantage of NAAT is that the tests can be relatively quickly updated for newly emerging pathogens and resistance factors. Quantitative PCR (qPCR) allows a rough quantification of microbes. Quantitative reverse transcription PCR (qRT-PCR) can additionally assess the expression level of resistance genes after exposure to different antibiotic loads and thus provide 
rough MIC values. The cost of devices and reagents for qRTPCR are unfortunately currently far beyond the level acceptable for routine AST. NAAT is a powerful tool for the identification of both bacterial and viral pathogens. In principle it allows the use of patient samples without enrichment cultivations. However, due to the risk of losing the template during nucleic acid extraction and the sensitivity of DNA polymerases to impurities in the sample matrix, enrichment cultivations and nucleic acid purification are often necessary. Due to the vast choice of different fluorescent labels, several target genes can be conveniently tested in parallel from the same sample. The systems can reach further sensitivity and specificity by applying hybridization to DNA arrays. A good number of FDAapproved multiplexed diagnostic panels are already available. Such commercial systems include Xpert ${ }^{\circledR}$ (Cepheid Inc.), ePlex (GenMark Diagnostics), Unyvero (Curetis AG), BD Max (Becton-Dickinson), SeptiFast (Roche), Magicplex (SeeGene), Novodiag (Mobidiag), and GenomEra (Abacus Diagnostics). The Xpert ${ }^{\circledR}$ technology combines sample preparation, real-time PCR and nucleic acid analysis with molecular beacons. The ePlex system provides electrochemical detection of the amplified sequences, wherein the detection is achieved by hybridizing ferrocene-labeled probes with the sample DNA (Nijhuis et al., 2017). Hybridization techniques and microfluidics have been implemented also to Novodiag's GenomEra microarray platform. It applies time-resolved fluorescence detection of the amplified product on a sealable plastic chip packed with dry chemistry. Also Curetis, Becton-Dickinson, Roche and SeeGene products apply cartridge-based integrated designs (Hughes, 2018). Fast analytics of PCR products enhance the throughput of NAAT systems. T2Biosystems has recently launched a test panel able to detect 13 resistance genes from both gram-positive and gram-negative pathogens directly from blood. The amplification products are detected by magnetic resonance after hybridization with DNA probes conjugated with superparamagnetic particles (Hong Nguyen et al., 2019).

PCR/electrospray ionization-mass spectrometry (IRIDICA PCR/ESI-MS by Abbott Laboratories Inc., USA) allows the detection of $>750$ different bacterial species in a single test (Strålin et al., 2016). The High Resolution Melting system (HRM, by ThermoFisher) identifies variations in nucleic acid sequences by detecting small differences in PCR melting curves. A melting curve analysis for real-time quantitative PCR or digital PCR (wherein the sample is partitioned into a large number of individual wells each containing either 1 or 0 targets) performed for growing bacterial cultures, revealed both ID and antimicrobial susceptibility profiles for E. coli, E. faecalis, $P$. mirabilis and $S$. aureus in $\sim 6.5 \mathrm{~h}$, when analyzed by machine learning algorithms (Athamanolap et al., 2017). For routine analytics, such systems are still too expensive, and they require separate kits for DNA extraction and PCR. However, new enzymes and technologies such as ligase chain reaction (LCR) (Barany, 1991), nucleic acid sequence-based amplification (NASBA) (Compton, 1991), strand displacement amplification (SDA) (Walker et al., 1992) and loop-mediated isothermal amplification (LAMP) (Notomi et al., 2000) have simplified nucleic acid amplification, made it more robust (often allowing the use of samples without NA extraction), enabled miniaturization and cut down the costs of instrumentation by allowing NAAT at a constant (isothermal) temperature. NUCLISENS ${ }^{\circledR}$ EASYQ ${ }^{\circledR}$ (bioMerieux) was the first automated system to combine NASBA and real-time detection using molecular beacon probes. It enabled the fast detection of Klebsiella carbapenemase genes (Spanu et al., 2012). LCR has been successfully used for the detection of ciprofloxacin and doxycycline resistance genes in Bacillus anthracis, Francisella tularensis, and Yersinia pestis (Oblath et al., 2013). LCR can be easily integrated into detection systems such as electrochemical and magnetic biosensors, quantum dots, quartz crystal and leaky surface acoustic surface biosensors, Surface Enhanced Raman Scattering (SERS), chemiluminescence and fluorescence resonance energy transfer (Oblath et al., 2013). High-throughput multiplex genotyping can be achieved also by DNAzyme (DNA oligonucleotides) technology, rolling circle amplification (RCA) and strand displacement amplification (SDA) techniques. LAMP is especially robust, since it is less sensitive to inhibitors than standard PCR. This allows analysis after a minimal processing of blood (Curtis et al., 2008), urine or stool (Francois et al., 2011). LAMP is applicable to low-resource field settings where DNA or RNA extraction is not possible. However multiplexing approaches are less developed for LAMP than for PCR (Sahoo et al., 2016).

\section{Immunodetection of Pathogens}

Immunodetection is a specific and sensitive method for the identification of bacterial pathogens (Verma et al., 2013), toxin proteins (Zhu et al., 2014), and viruses. Since immunodetection does not necessarily require disruption of the target microbes, it can potentially provide pathogen identification and growth monitoring in a single step. It is applicable as simple lateral flow (LF) tests, but can also be integrated to biosensor technology, microfluidics and even to DNA/RNA-based analysis. Companies like Mizuho Medy, Alere, and Beckton Dickinson have launched several easy-to-use stick tests for clinical diagnostics of (influenza) viruses and bacteria causing sexually transmitted diseases. The binders are typically antibodies that are immobilized onto strips, micro/nanoparticle beads or biosensor surfaces providing an efficient and specific target binding. The detection antibody can be labeled with fluorescent dyes or redox enzymes to provide a quantitative signal.

Only few products are available for the direct detection of antibiotic resistance proteins. The LF-test developed by Kitao et al. detects chloramphenicol resistance in $P$. aeruginosa samples (Kitao et al., 2010). Alere Inc. has launched an immunochromatography test for the detection of MRSA, based on a PBP2a-specific chicken IgY antibody (Yamada et al., 2013). The PBP2a SA Culture Colony Test can identify MRSA in 6 min (Trienski et al., 2013; Delport et al., 2016). Coris Bioconcept (Belgium) has launched tests for the detection of carbapenemases (OXA-48-like, KPC, and NDM type) from enterobacterial isolates (Bogaerts et al., 2013; Glupczynski et al., 2017). Boutal et al. have presented LF tests for the carbapenemases TX-M15, NDM, OXA-48-like, KPC, IMP, and VIM (Boutal et al., 2017). LF tests work well with isolated clinical isolates. They are, 
however, generally not applicable for direct analysis of clinical samples. The commercial MultiPath ${ }^{\mathrm{TM}}$ platform (First Light Diagnostics Inc., USA) applies non-magnified digital imaging for the detection of biomolecules tagged with antibody-coated fluorescent nanoparticles. The mariPOC ${ }^{\circledR}$ system by ArcDia Ltd, based on Two-Photon eXcitation fluoroscopy technology (TPX), is already in diagnostic use for immunogenic detection of pathogens. These two technologies will be discussed closer in the following sections.

\section{FUTURE TECHNOLOGIES UNDER COMMERCIALIZATION}

Mass spectrometry is likely to become tightly integrated into other AST technologies, especially in the diagnostics of septicaemia. In the MALDI-TOF Direct-On-Target Microdroplet Growth Assay (DOT-MGA), sample droplets (culture plus antibiotics in $6 \mu \mathrm{L}$ volume) are spotted directly onto disposable MS-target plates, incubated for 3-4 h and then analyzed with MS (Idelevich et al., 2018). Screening panels for ESBL and AmpC $\beta$-lactamases of enterobacteria are already available (CorreaMartínez et al., 2019). The fast progress in microfluidics, biosensor technologies, isothermal amplification-based NAAT, and immunodetection has recently provided several potent systems which may eventually change the paradigms of AST.

Gradientech's QuickMIC system combines microfluidics with automated time-lapse photomicrography to follow growth inhibition along a linear drug gradient. It measures the greyscale intensity changes in the images caused by the formation of microcolonies and provides AST in 2-5 h (Malmberg et al., 2016). The system is currently seeking CE-IVD marking and FDA approval for AST in blood samples.

Q-Linea ASTar ${ }^{\circledR}$ applies time-lapse microscopy to fully automated monitoring of blood cultures as well as preparation and monitoring of bacterial isolates. It processes 12 samples at a time and 50 samples a day, delivering true MIC values for up to 48 antibiotics within $6 \mathrm{~h}$. The system does not perform ID, but it can be connected to any ID system. Clinical trials will start in 2020.

The BacterioScan 216Dx system (St. Louis, MO, USA) measures both a sample's optical density (OD) and the scattered intensity by forward laser light scattering, allowing 10-100-fold higher sensitivity compared to normal OD measurements. This system can process 16 samples simultaneously and perform realtime continuous growth measurement. It can detect bacterial growth in $3 \mathrm{~h}$ from clinical urine samples containing $>10^{4}$ $\mathrm{cfu} / \mathrm{ml}$ of E. coli, Staphylococcus aureus, Pseudomonas aeruginosa, Bacillus antracis, Yersinia pestis, or Burkholderia pseudomallei (Bugrysheva et al., 2016; Hayden et al., 2016; Montgomery et al., 2017). The BacterioScan 216R Rapid AST System is currently under testing.

The oCelloscope ${ }^{\mathrm{TM}}$ system (BioSense Solutions, Denmark) applies digital time-lapse angled field microscopy and image analysis for standard 96-well plates. The time-to-result for positive blood cultures ranged from 1 to $4.2 \mathrm{~h}$ (Fredborg et al., 2015). However, the overall performance for AST has not yet been sufficiently tested.
Changes in individual cell morphology or size indicate growth long before bacteria have multiplied. Single-cell morphological analysis (SCMA) uses bright-field microscopy to determine antibiotic-induced changes in cells immobilized on an agarose channel chip (Choi et al., 2014). The commercial MultiPath ${ }^{\mathrm{TM}}$ platform applies non-magnified digital imaging for the detection of biomolecules tagged with antibody-coated fluorescent nanoparticles. Antibody-coated magnetic particles are used to bind to target cells and to pull them down to the camera surface, thus eliminating background signal and enabling a wash-free assay for clinical samples. The system counts individual targets in large areas and performs growth monitoring for multiple targets cells and enables the determination of MIC values. The MultiPath ${ }^{\mathrm{TM}}$ system is currently seeking FDA clearance.

The Two-Photon eXcitation fluoroscopy technology (TPX), commercialized by ArcDia Ltd. (Finland), allows separation-free detection of biological molecules in small reaction volumes by immunodetection (Vakkila et al., 2015). The mariPOC ${ }^{\circledR}$ test system was developed for rapid pathogen identification. It applies polystyrene microparticles as solid carriers for immunocomplex formation, that leads to three-component immunocomplexes (monoclonal antibody-antigen-labeled monoclonal antibody) on the microspheres in proportion to the analyte concentration. The detection of the immunoassay fluorescence signal is achieved by two-photon excitation from the surface of individual microspheres. This mechanism allows the use of unpurified clinical samples and on-line monitoring of viable cells in AST cultures. At present this system is under clinical testing for AST.

Nanostring Technologies Inc. combine genotypic and phenotypic AST through RNA detection. The GoPhAST-R platform detects mRNA expression signatures in bacteria after antibiotic exposure. The system can be used directly for positive blood culture bottles. It couples machine learning analysis of transcriptional changes with the detection of resistance genes (Bhattacharyya et al., 2019).

Colorimetric sensor arrays provide an inexpensive method to detect volatile organic compounds (VOCs) associated with microbial metabolism (Lonsdale et al., 2013; Lim et al., 2014). Specific Technologies Inc (USA) has commercialized the small molecule sensor (SMS) array technology which reacts with the metabolic products of bacteria produced during their growth. Their Reveal-AST printed sensor array system responds to the volatiles emitted during growth producing a colorimetric pattern. It reveals also species ID with 94\% accuracy (Sharp, 2020).

The SlipChip/dLAMP technology by Caltech integrates seamlessly cultivation and semiquantitative smartphone-based visual analysis of NA products (Schoepp et al., 2017). This system, currently being commercialized by Talis Inc. (USA), will be described closer in the chapter "POCT-compatible technologies."

\section{Whole Genome Sequencing}

Progress in Whole Genome Sequencing (WGS) technologies has made them a feasible system for pathogen ID and AST (van Belkum and Rochas, 2018). 3rd generation systems such as Illumina MiniSeq, Pacific Biosciences PacBio Sequel system, or Oxford Nanopore MiniON and PromethION can provide fairly long reads at high speed. In principle, WGS can simultaneously 
provide fast pathogen ID, epidemiological typing, and detection of drug susceptibility genes. Since WGS provides a massive amount of data in fragmented form, sophisticated software is needed to interpret the results (Quainoo et al., 2017). The European Committee on Antimicrobial Susceptibility Testing reviewed in 2017 the development status of WGS for AST (Ellington et al., 2017). They concluded that, for most bacteria, the available evidence for WGS as an AST tool is still either poor or non-existent and thus inadequate for clinical decision making. They pointed out the urgent need for a single database of all known resistance genes/mutations to facilitate comparison between different systems and bioinformatics tools.

\section{PROOF-OF-CONCEPT TECHNOLOGIES}

\section{Smartphone-Based Readers}

Kadlec et al. combined smartphone technology to a microphotometric system applying microwell plates coated with antibiotics and the yellow redox indicator dye tetrazolium salt WST-8, which turns orange by the metabolic activity of growing cells. The system could correctly monitor the growth of several pathogens associated with urine tract infection. Samples with concentrations of $10^{1}$ to $10^{6} \mathrm{cfu} / \mathrm{mL}$ could be tested directly without preliminary enrichment cultivations (Kadlec et al., 2014). Feng et al. presented an automated smartphone-based device with a 3D-printed attachment holding a microwell plate. A light-emitting diode array and fiber-based optics enabled detection of turbidity changes in wells already after 1 min (Feng et al., 2016). This system, tested for 17 antibiotics targeting Gram-negative bacteria on clinical isolates of K. pneumoniae, provided drug susceptibility interpretation with accuracy of $99.23 \%$. Cui et al. have presented a smartphone-based system for the monitoring of viable bacteria in droplet-based single-cell microdroplet cultures (Cui et al., 2018). In this system, single bacteria were encapsulated in monodisperse microdroplets. This dSPC (Digital Standard Plate Count) platform could quantify $E$. coli and B. subtilis in $6 \mathrm{~h}$, compared to $24 \mathrm{~h}$ needed for traditional plate counting. These smartphone demonstrations discussed above were performed using pure culture isolates.

Smartphone-based systems applying immunodetection have been demonstrated for ID, but so far not for growthbased AST. Wang et al. introduced a microwell plate-based microphotometric system, which applied a field-of-view adapter and a microprism array between the mobile phone camera and the 96-well plates. In a serological analysis (771 patient samples in 12 serology assays for bacterial/viral infections) the system exhibited $97.59 \sim 99.90 \%$ analytical accuracy in pathogen identification with costs of $\sim 50$ USD per 96-well plate and analytical quality sufficient for POCT (Wang et al., 2018).

An inexpensive (under 100 USD) smartphone-based monitoring system for nucleic acid amplification, smaRT-LAMP, was introduced by Barnes et al. The system contains a hot plate for isothermal amplification, two flexible cables and 96 LED lights fitted into a cardboard box. The Bacticount software detects the emitted green light as a result of a successful amplification and automatically determines the genome copy number in real time. smaRT-LAMP was shown to work well with diverse Gramnegative and Gram-positive pathogens in biological specimens, giving in $\sim 1 \mathrm{~h}$ results with matched standard cultivation-based tests. Reliable pathogen ID was obtained for spiked urea and blood samples as well as for urea samples of sepsis patients $\left(10^{5}\right.$ $-10^{8}$ CFUs). The small sample size ( $2 \mu$ l per reaction), however, limits its use for very diluted samples (Barnes et al., 2018).

Priya et al. have successfully coupled loop-mediated isothermal amplification (RT-LAMP) and sensitive quenching of unincorporated amplification signal reporters (QUASR) detection technologies to visual detection with a smartphone. The portable "LAMP box" was successfully used for the sensitive and specific detection of Zika, chikungunya, and dengue viruses (Priye et al., 2017). This system has not yet been applied to growth-based AST.

\section{Optical or Microscopic Methods}

Choi et al. have developed a rapid antimicrobial susceptibility testing system, dRAST. It can determine the AR from a positive blood culture bottle in $6 \mathrm{~h}$ (Choi et al., 2017). The sample is mixed with agarose and inoculated into a well of a plastic microchip. Addition of cultivation medium forms a liquid bridge between the growth chamber and the satellite well, which contains the antibiotic agent. Using microscopic detection of bacterial colony formation in agarose, the total time-to-result was only $6 \mathrm{~h}$ with a wide range of bacterial concentrations. The tested clinical isolates $(n=206)$ included 16 Gram-negative species and seven Grampositive species, and the dRAST system agreed with a standard microdilution test with an accuracy rate of $91.11 \%$ (Choi et al., 2017).

Matsumoto et al. described a microfluidic channel method for rapid ( $3 \mathrm{~h}$ ) AST for P. aeruginosa by automated microscopic detection of cell number and cell morphology (Matsumoto et al., 2016). Their Drug Susceptibility Testing Microfluidic device (DSTM) consisted of five sets of four microfluidic channels and allowed simultaneous microscopic observation. Susceptibilities to the antibiotics (pre-dried into each channel) were evaluated by the differences in cell number and shape between drug-treated and control cells. Hundred and one clinically isolated strains of $P$. aeruginosa tested with DSTM correlated strongly with the results obtained using the conventional microbroth dilution method (Matsumoto et al., 2016). This system waits for applicability testing with other organisms.

In nanowell AST, morphotyping with a phase contrast microscopy and optical signal analysis is performed for 0.5 $\mu l$ cultures. Antibiotic susceptibility data can be obtained for uropathogens in $<4 \mathrm{~h}$. The system showed a total categorical agreement of $97.9 \%$ with standard disk diffusion assays, but a careful standardization of cell densities prior to cultivation was found necessary (Veses-Garcia et al., 2018).

\section{Hybridization Methods}

Mezger et al. presented a generic method for rapid species identification and AST after 0.5-2 h cultivation (Mezger et al., 2015). Cultured bacteria from urine samples were lysed by sodium hydroxide and heat, and DNA was captured onto magnetic beads. Padlock probes targeting the $16 \mathrm{~S}$ rRNA gene 
were hybridized, ligated and amplified by the circle-to-circle amplification method. Optical imaging system then performed digital quantification. Antibiotic susceptibility profiles of E. coli for ciprofloxacin and trimethoprim could be determined with $100 \%$ accuracy in $3.5 \mathrm{~h}$ (Mezger et al., 2015).

\section{Detection of Growth-Related Molecules or Antibiotic Degradation Products}

Devices detecting volatile compounds, so-called electronic noses (eNose), can recognize a smell-print characteristic for bacterial species and their metabolic profile. Since 1982, electronic noses have been applied in diagnostics (Persaud and Dodd, 1982), but mainly for pathogen ID. The Cyranose system (Smiths Detection) was able to distinguish between controls and samples positive for S. aureus, S. pneumoniae, Haemophilus influenzae, and $P$. aeruginosa in upper respiratory tract infections (Lai et al., 2002). Gas chromatography connected to ion mobility spectrometry (GC-IMS E-nose) could reliably distinguish bacterial infections from viral respiratory tract infections (Lewis et al., 2017). Saviauk et al. performed an applicability test for the ChemPro 100i Ion Mobility Spectrometry sensor (Environics Inc.). They could discriminate MRSA from MSSA with 83\% sensitivity and $100 \%$ specificity (Saviauk et al., 2018) and were able to identify also other pathogens (P. aeruginosa, Enterococcus, E. coli, and Clostridium perfringens) from culture plates with $78 \%$ accuracy. In order to access the AST market, the eNose systems should outperform the simple and inexpensive colorimetric sensor array system "Reveal-AST" (Specific Technologies, USA) which is applicable to growth-based AST.

\section{NAAT in Growth Monitoring}

Real-time qPCR can detect quantitative differences between cultures exposed to various antibiotics and different concentrations. Already a $15 \mathrm{~min}$ cultivation can provide a detectable increase of nucleic acids (Schoepp et al., 2017). Although qPCR devices are expensive and require experienced personnel for their operation, low-cost devices based on isothermal amplification might change the game thoroughly. Applying chip electronics and microfluidics, CalTech (the Technical University of California) has developed a device applicable to AST. This system is currently under commercialization by SlipChip Corp and will be described closer later in this review in the section "POC-compatible technology."

\section{Biosensor Systems}

Biosensors are devices that measure biological or chemical reactions by generating signals proportional to the concentration of an analyte in the reaction. Exposure to antibiotics causes detectable changes in bacterial membranes, morphology, metabolism, movements, mass, heat production and nucleic acid content. In microcalorimetry approaches, heat production correlates with the number of cells arising over time (von Ah et al., 2009). This approach is applicable to both solid and liquid cultures (Howell et al., 2012). Dynamic heat flow patterns have served species identification from urine samples (Bonkat et al., 2012). Isothermal microcalorimetry revealed vancomycin-resistant Staphylococcus aureus in $<8 \mathrm{~h}$ (Entenza et al., 2014). Butini et al. applied isothermal microcalorimetry to real-time monitoring of microbial viability in biofilms in the presence or absence of antimicrobial compounds (Butini et al., 2018). Microcalorimetric methods, although fast and sensitive, require pure cultures and a fairly high number of bacterial cells. In 2017, the Swedish company SymCel announced an extensive 28-months clinical testing of their microcalorimeter calScreener ${ }^{\mathrm{TM}}$ for AST. However, currently no clinically validated microcalorimetry systems are available.

For some antibiotics (beta-lactams, chloramphenicol) AMR can be assayed by the follow-up of antibiotic degradation. The BYG Carba test detects conductivity changes caused by the enzymatic hydrolysis reaction of imipenem antibiotics on an electrode coated with polyaniline, which is highly sensitive to changes in $\mathrm{pH}$ or redox potential. With a loop-full of bacteria (10 $\mu \mathrm{l})$ from a fresh plate as a sample, this home-made inexpensive instrument could detect carbapenem resistance in $<35 \mathrm{~min}$ displaying $95 \%$ sensitivity and $100 \%$ specificity in comparison to PCR-based analysis (Bogaerts et al., 2016). Mecklenburg et al. developed an assay that directly detects the thermal signal generated from the enzymatic breakdown of antibiotics. The system was able to distinguish between penicillinase and metallo$\beta$-lactamase (Mecklenburg et al., 2017). Its value for clinical work needs to be evaluated, as it requires pure cultures and does not provide pathogen ID.

A variety of electrochemical reporters for cell viability have been applied to viability analysis and drug susceptibility measurements. The system by Besant et al. uses resazurin dye (an oxidation-reduction indicator) to monitor cells trapped in nanoliter wells (Besant et al., 2015). Within $1 \mathrm{~h}$ the microfabricated device could detect the response of $E$. coli and K. pneumoniae exposed to ampicillin and ciprofloxacin in urine samples spiked with bacteria in concentrations as low as $1 \mathrm{cfu} / \mu \mathrm{L}$. The level of commercialization of this technology is not known.

In microelectromechanical systems (MEMS) the deflections associated with the micromotions of bacteria attached to a microcantilever provide a signature of bacterial metabolism. Such changes can indicate growth long before the bacteria replicate. With bacteria captured in bi-material microchannel cantilevers, quantitative antibiograms have been obtained for $E$. coli and S. aureus within $2 \mathrm{~h}$ (Etayash et al., 2016). The bacteria absorb infrared photons and release heat to the support matrix by a process of vibrational energy relaxation, inducing bending of the bimetallic cantilever proportional to the quantity of the released energy. High sensitivity, corresponding to a single cell per $\mu \mathrm{l}$, was obtained with Listeria-containing samples. The researchers plan to further integrate sample separation techniques into this BioMaterial Cantilever platform. LifeScale Analytics (NC, USA) has already launched a commercial product which correlates cantilever vibration to biomass for MIC determination (Burg et al., 2007). This system performs automated cell counting, mass measurement, and visual observation of liquid samples for AST in $<3 \mathrm{~h}$, but requires cell concentrations above $10^{4}$ cells $/ \mathrm{ml}$. The company has not yet presented peer-reviewed clinical AST studies for this instrument. Micromotions are affected by flowing liquids, and inefficient transfer of antibiotics to immobilized bacteria can distort the results. Therefore pre-enrichment and pre-purification of bacteria may be necessary (Li et al., 2017b; Syal et al., 2017). 
A low-cost and rapid biosensor has been developed employing photoluminescence emission of photo-corroded GaAs/AlGaAs biochips. Growing bacteria protect the biosensor surface against photo-corrosion, while non-growing or dead cells give a higher signal. These biochips exposed to a E. coli and Legionella pneumophila cultures (w/o antibiotics) were capable of quantifying electrically charged bacteria in $4.5 \mathrm{~h}$ (Nazemi et al., 2017).

The Field Effect Enzymatic Detection (FEED) biosensor platform can detect extremely low bacterial concentrations (below 10 c.f.u./ml). An electrical field between the working electrode and the immune complex multiplies the biocatalytic output current, enabling a direct detection of bacteria without sample processing (Shi et al., 2018). These biosensors apply horse radish peroxidase (HRP) as a redox source in the sandwich hybridization complex. Commercial devices applying this technology for AST may potentially emerge in coming years.

\section{Other Proof-of-Concept Technologies}

Flow cytometry (FC) can provide excitation/emission spectra of cells and give information about cell-counts, morphology and viability, enabling AST in 2-3 h. Due to the large amount of raw data, mathematical methods such as adaptive multidimensional statistics must be applied for analysis (Huang et al., 2015). Successful demonstrations with clinical polymicrobial samples are currently missing. Flow cytometric assays struggle with complex patient samples, inefficient staining, the presence of autofluorescence, the inability to differentiate cellular damage for the influence of antibiotics, and lack of clinical databases for validation. Flow cytometry instruments are very costly, making this technology an unlikely candidate for POCT. Atomic force microscope (AFM) allows real time monitoring of bacterial activity. This principle is applicable to both cultivable and non-cultivable cells (Longo et al., 2013), but is an expensive and tedious system for clinical work. Plasmonic imaging and tracking (PIT) can be used for the monitoring of nanometerscale motions of single bacterial cells before and after antibiotic addition. The observed image contrast fluctuations were found to indicate changes in bacterial metabolism long before cell replication (Syal et al., 2016). Asynchronous magnetic bead rotation $(\mathrm{AMBR})$ is a non-microscopy-based approach capable of monitoring individual cells for elongation, generation time, lag time, division, as well as sensitivity to antibiotics. It has been successfully tested with $E$. coli attached to anti-E. coli functionalized beads (Kinnunen et al., 2011). This system is still at the research stage and a complex technology regarding handling, setup and the need for expertise (Schumacher et al., 2018).

\section{MINIATURIZED AND CHIP-BASED GROWTH MONITORING SYSTEMS}

Lab-on-a-chip systems combine one or several laboratory functions into a single integrated circuit. The microfluidic AST platforms typically apply channels containing pre-loaded dried antibiotics. Following on-chip cultivation, the channels can be monitored with a detection device such as a phase contrast microscope. Some systems use agar to immobilize the bacteria and to form growth chambers. Also gradient-forming microfluidic platforms have been applied (Luka et al., 2015; Campbell et al., 2016). He et al. introduced a chip applying antibody-coated glass beads to capture E. coli O157 and to provide fluorescence detection for ID and AST. Their device had an integrated antibiotic release system, which could identify this strain at a range of $10^{4}-10^{8} \mathrm{cfu} / \mathrm{ml}$ within $30 \mathrm{~min}$ (He et al., 2014). Li et al. integrated antibody-coated carbon nanotubes with isothermal amplification. The carbon nanotube multilayer could perform selective capture, cultivation and release of the bacteria. After cultivation the antibody-entrapped bacteria were lysed, and their DNA was accurately quantified by LAMP. This system could detect E. coli O157:H7 and its toxin at concentrations as low as $1 \mathrm{cfu} / \mathrm{ml}$ without any complicated instrumentation ( $\mathrm{Li}$ et al., 2017a). Its use for growth-based AST has not yet been presented. Researchers at Hong Kong Baptist University have developed a multidimensional AST system for growth-based AST, providing detection through automated microscopy in $4 \mathrm{~h}$. They established a hydrogel microfluidic chip which simulates drug diffusion and pathogen killing processes inside the human body. Due to the chip's multidimensionality, several antibiotics, nutrients or immunologic substances could be tested simultaneously. This system is currently under commercialization (Sun et al., 2016; Liu et al., 2017a,b). Weibull et al. have presented a nanowell AST device capable of real-time optical reading and growth data analysis. This "stationary nanoliter droplet array" (SNDA) system can provide ID and AST for urine samples within one working shift. A filtering process first isolates bacteria from the clinical urine samples into a growth medium, supplemented with $10 \%$ resazurin (oxidation-reduction indicator). Applying 12 bacteria-antibiotic combinations precise MIC determinations could be obtained in $3 \mathrm{~h}$, which is 6 -fold faster than traditional broth microdilution assays in 96-well plates. However, follow-up studies with clinical isolates of both Gram-negative and Grampositive bacteria are needed (Weibull et al., 2014). Veses-Garcia et al. applied $0.5 \mu \mathrm{l}$ cultures for uropathogens on a 672-nanowell slide equipped with optical signal analysis. They were able to define a precise minimum inhibitory concentration for 70 clinical E. coli isolates. Algorithm-assisted optical analysis determined antibiotic susceptibility in $3 \mathrm{~h} 40 \mathrm{~min}$, showing a total categorical agreement of $97.9 \%$ (Veses-Garcia et al., 2018).

The "Integrated Comprehensive Droplet Digital Detection" (IC 3D) system is capable of detecting bacteria directly from diluted blood within 1.5-4h. It consists of bacteria-specific DNAzyme-based sensors, a droplet microencapsulation system, lysozyme and a 3D particle counter system. The ongoing work aims to develop an automated, portable device for multiplexed and rapid detection of antibiotic-resistant strains (Kang et al., 2014). The Ultrafast Parallelized Microfluidic Platform consists of four arrays (each holding $110 \mathrm{pL}$ droplets with 1-4 bacteria) which are screened by dynamic imaging over $2 \mathrm{~h}$. This imaging-based AST was successfully tested with four types of pathogens causing urinary tract infection (UTI) (Kang et al., 2019). 


\section{POCT-COMPATIBLE DEVICES FOR ID AND AST}

Systems with a low price and high speed are needed in all healthcare sectors, but especially in outpatient clinics and in developing countries. Point-of-Care Tests (POCT) could bring the diagnostics into outpatient clinics and thus facilitate evidence-based medication in places where extensive prescription of antibiotics happens. Very few rapid AST systems are currently available, but the ongoing development is promising. David Boyle has made an excellent review of affordable technologies and devices applicable to "standard microscopy stations" (Boyle, 2017). The devices presented below can provide a fast pathogen identification. Some of these are already now applicable to AST, and some devices can be even applied to diagnostics of non-infectious diseases as well.

Scanogen Inc. (USA) develops DNA-based (nonamplification-based) "single-molecule biosensors" bound to microparticles, which can convert the hybridization signal to an optical signal. The device contains an inexpensive and low-power light-emitting diode ring and uses disposable sample cartridges, abolishing the need for manual sample preparation. The company is currently developing diagnostic assays for infectious diseases and drug resistance. The MicrobeDx technology (MicrobeDx Inc., CA, USA) applies a transformational ribosomal RNA-based assay on a microfluidic disc platform. The disc holds 150 nucleic acid capture probes spotted onto a glass slide. This system can discriminate four clinically relevant Staphylococcus species that differ by a single nucleotide polymorphism (SNP) in diagnostic probe sequences. The protocol includes hybridization, washing, rinsing, and drying steps and does not require purification of the target nucleic acids (Peytavi, 2005). In a clinical testing phase financed by NIH during the years 2018-2019 (so far unpublished), MicrobeDx has tested UroLogic, a highly automated instrument and cartridge system that performs rapid pathogen ID and AST in 30 and $150 \mathrm{~min}$, respectively. The Alveo platform (Alveo Technologies Inc, CA) applies hybridization-based electrochemical nucleic acid detection in single-use cartridges. The cloud-connected device is capable of analyzing 100 infectious diseases. Sample preparation, nucleic acid amplification, and real-time hybridization-based detection are performed in a single isothermal microfluidic channel. This concept has not yet been applied to growth-based AST. The Loopamp ${ }^{\mathrm{TM}}$ technology by Eiken Chemical Corp. (China) has already received WHO endorsement for tuberculosis diagnostics (Noncommercial culture drug-susceptibility testing methods for screening patients at risk for multidrug-resistant tuberculosis: policy statement, 2011). The Loop-mediated isothermal amplification (strand displacement reaction) employs four different primers designed for six distinct regions on the target gene. It has been used successfully for the detection of Neisseria meningitidis in clinical cerebrospinal fluid samples (Lee et al., 2015) and for the detection of the OXA-23 carbapenemase (Yang et al., 2018) gene of Acinetobacter baumannii.

Schoepp et al. (2017) demonstrated with 51 clinical samples that the antibiotic exposure time in phenotypic AST can be shortened to $15 \mathrm{~min}$ when dLAMP (digital real-time loop-mediated isothermal amplification) or dPCR (droplet-PCR) is applied. The changes in DNA concentrations (control vs. antibiotic-treated samples) were determined by a "digital singlemolecule counting" system after incubation. In dLAMP, the target molecules or lysed cells are partitioned into thousands of nanodroplets so that each compartment contains approximately a single molecule (Schoepp et al., 2017). The $1 \mathrm{nl}$ droplets with DNA concentrations relevant to clinical urine tract infection samples showed 1.23-fold difference in amplification products between resistant and susceptible strains, and $98.1 \%$ of the tested samples matched the standard AST results. The LAMP chemistry was optimized and applied to a SlipChip microfluidic device equipped with an electrophoretic system concentrating the bacteria in the sample. This concept was tested for AST of positive blood cultures. The results were consistent with standard microdilution tests or the BD Phoenix System when several broad-spectrum antibiotics and clinical E. coli samples as well as the $S$. aureus ATCC 6538 strain were tested (Yi et al., 2019). The Talis Biomedical Corporation (CA, USA) is currently commercializing dAST/SlipChip technology to a product which combines a single-use cartridge integrating fluid partitioning for parallel treatment with different antimicrobials, reagent additions, target lysis, extraction and amplification. The NAAT-based system presented by Priye et al. (2017) applies a reverse-transcription loop-mediated isothermal amplification (RT-LAMP) coupled with the QUASR technique (quenching of unincorporated amplification signal reporters). The device was found to be five times more sensitive than traditional POCT for the detection of the dengue, chikungunya, or Zika viruses. Hassibi et al. have presented a fully integrated, miniaturized semiconductor biochip with closed-tube detection chemistry for multiplex NA amplification and sequence analysis, which they claimed to have a high dynamic quantification range for the microbial load, while at the same time performing comprehensive mutation analysis on up to 1,000 sequences or strands simultaneously in $<2 \mathrm{~h}$. This chip was able to correctly detect and quantify multiple DNA and RNA respiratory viruses in clinical samples, while at the same time detecting 54 drugresistance-associated mutations in six genes of Mycobacterium tuberculosis (Hassibi et al., 2018). QuantuMDx Ltd (UK) aims to launch a miniaturized portable diagnostic platform that runs on battery power. This Q-POC ${ }^{\mathrm{TM}}$ device would be a portable molecular diagnostic instrument with built-in NA amplification for multiplexed diagnostics and drug susceptibility testing within $20 \mathrm{~min}$. It applies nanowires coated with specific probes for the detection of genetic variants and has cloudbased connectivity to share and utilize epidemiologic data. This technology is currently under clinical evaluation for diagnostics of malaria (protozoan Plasmodium falciparum) and tuberculosis (Mycobacterium tuberculosis). The device, although not designed for growth-based AST, might have a very wide applicability range including non-infectious diseases such as cancer or genetic disorders. The outcome of the clinical tests has not yet been published. The Multipath instrument (First Light Diagnostics Inc., USA) applies fluorescence-labeled nanoparticles attaching to the target cells by immunobinding. The nanoparticle/cell complex can then be pulled toward the detection system 
by magnetic beads conjugated with another microbe-specific antibody. Thereby the system is capable of monitoring viable cells using non-magnified digital imaging. A POCT-compatible device is currently under testing. Immunodiagnostic TPX-technology (two-photon excitation fluorometry), commercialized by ArcDia Ltd (Finland) to mariPOC and mariAST platforms, can analyze 40-100 samples a day. It has a cloud-based connectivity allowing efficient sharing of epidemiologic data. TPX allows the use of untreated polymicrobial clinical samples on-line, providing bacterial ID in $20 \mathrm{~min}$ and antibiotic resistance in a few hours. Unlike most other AST systems, it can also provide sensitive immunodetection of viruses Sanbonmatsu-Gámez et al., 2015; Bruning et al., 2018.

POCT devices using smartphone technology have long been used for personalized medication applications such as the colorimetric analysis of urine strips (Barnes et al., 2018). The use of smartphones in growth-based AST for miniaturized cultures has been presented in several studies (Kadlec et al., 2014; Schoepp et al., 2017; Cui et al., 2018; Hernández-Neuta et al., 2019), although instrument manufacturers seem to be reluctant to incorporate standard commercial smartphones to their systems. Photolithography, plotting, plasma etching, inkjet printing, cutting, and wax printing can be used to pattern paper for inexpensive diagnostic tests (López-Marzo and Merkoçi, 2016). Paper-based systems have been applied for the immunodetection of Helicobacter pylori, Chlamydia infections and Zika virus infections, but platforms integrating LF-testing into growthbased AST have not been presented.

\section{PROBLEMS WITH MINIATURIZATION AND RAPID AST}

Due to the small sample size (at lowest a single bacterial cell), rapid AST may not give results representing the whole bacterial population in the diagnostic sample. This problem can be mitigated by analyzing a large number of individual cells. An example of such a strategy is the stochastic confinement of bacteria in nanoliter droplets, so that a high number of individual droplets can be analyzed quickly and efficiently (Boedicker et al., 2008). The direct analysis of clinical samples also demands the use of valid internal standards. Additionally any growth-based analysis may utterly fail if the growth rate is very low or the microbes cease to grow due to the lack of specific growth factors, a non-optimal atmosphere, or the accumulation of growth-inhibiting substances. For intracellular pathogens the use of NAAT may be necessary. Compared to standard microbial cultivations, favorable growth conditions may be difficult to establish for miniaturized set-ups. These problems can be mitigated by analyzing cell viability, morphology or movements. Miniaturization can improve the performance and capacity of cultivation-based AST only if the need for manual steps is minimized. As reagent dilutions are often done before loading onto the chip device, set-up complexity may stay a similar level as in broth dilution methods. Due to the relatively low number of pathogens in most clinical samples and the impurities of the sample matrices, miniaturized cultivations benefit from methods concentrating the cells and removing the impurities. The FISH-based Accelerate Pheno system applies electrokinetic/electrophoretic system for these purposes. Coarse cell sorting for blood samples can be achieved through simple inertial microfluidic systems, where centrifugal (inertial) force drives bacteria to the outer side of a spiral-formed microcapillary tube, while blood cells stay on the inner side (Bhattacharyya et al., 2017). Some systems bypass the problem of impurities by bringing the target close to the biosensor surface with magnetic and antibody-coupled beads or nanoparticles. Miniaturization sets high demands to the standardization of the conditions, as the samples should represent similar growth states and culture densities. Robots may be needed for accurate pipetting.

Serious doubts concerning the ability of accelerated cultures to fully substitute standard growth-based tests have been presented. Accelerated cultivations may struggle to differentiate between wild type and resistant strains (Leclercq et al., 2013; Kahlmeter, 2014; Maurer et al., 2017). This is especially a concern in the case of induced expression of the resistance factors, e.g., in the detection of AmpC in enterobacteria or macrolide-resistance in streptococci (Leclercq and Courvalin, 2002; Jacoby, 2009; Harris and Ferguson, 2012).

\section{ECONOMIC DRIVERS FOR RAPID AST}

Substantial overall savings can be obtained with rapid AST through the reduction of hospital days, disability days and the saving of lives (Cassini et al., 2019). Despite the potential total cost savings, the high price of molecular testing forms an efficient barrier for the installation of new technologies. A price tag ranging from $\$ 100$ to $\$ 250$ per test is common for molecular tests (Li et al., 2017b). For a typical 500-bed community hospital, detailed multiplex testing of positive blood cultures by NAAT could cost more than $\$ 500,000 /$ year in reagents alone (She and Bender, 2019). Also the instrument prices may be significant. The total costs of testing are quite difficult to estimate. The prices of test kits and diagnostic instruments are based on the distributors' offers. Testing costs include clinical sampling and usually also cultivations in microbiology labs (enrichment, preparation of bacterial isolates) before AST can be performed. As an example, Patel et al. estimated the total costs for mass spectrometry-based AST to be roughly $79 €$ per patient, when the cost of the MALDI-TOF device, reagents, pharmacist time and the antimicrobial stewardship program are pooled together (Patel et al., 2017). Yet the reagent costs for one MS-sample can be pressed close to $1 €$. A typical MALDI-TOF MS system with all the accessories, software databases and maintenance is costly (up to $€ 200,000$ per year) (Wieser et al., 2012). This implies that the use of the instrument must be high for an acceptable cost efficiency. This unfortunately rules out their use in outpatient clinics. MS-instruments are, however, very versatile and can be applied also to other routine diagnostics in central laboratories (Vrioni et al., 2018). Direct inoculation from plates to automated identification systems such as Vitek, Microscan and others has been validated and used in many clinical laboratories. These systems apply multiwell liquid cultures and have a turnaround 
time as short as $4 \mathrm{~h}$ for ID and 6-8 $\mathrm{h}$ for AST (She and Bender, 2019), but the prices of these instruments are high. The cost of any rapid AST should not significantly exceed the cost level currently considered acceptable for routine testing: this might be roughly 30 to $50 €$, including sampling, culturing and AST (EU, 2013). Five phenotypic tests for a targeted detection of enterobacterial carbapenemases have been recently evaluated for their performance and costs. All these tests required the use of culture isolates. Per sample, the costs of multiplexed PCRbased analysis was $30 €$, immunochromatographic methods $\sim 15 €$, a colorimetric assay $5 €$ and carbapenem hydrolysis test $1 €$ per sample (Baeza et al., 2019). Apart from turnover time, also the capacity of the test system is important. Among automated microscopy systems, Accelerate Pheno handles one sample per unit module (max. four modules per device, cost per sample $\sim 250 €$ ), whilst the Q-Linea ASTar system can handle 50 samples per day. The capacities of NAAT-based systems can be even higher. Automated MIC-determination systems such as VITEK-2 can manage tens of samples per time. For POCT usage, however, a throughput capacity of a few tens of samples per time would be sufficient.

\section{SUMMARY: HOW DO THE AST TECHNOLOGIES MEET THE REQUIREMENTS?}

Several identification systems based on NAAT, NA hybridization and immunodiagnostics are already available for rapid diagnostics, but only few are applicable to POCT. This is due to high costs, lack of appropriate facilities or expert labor, or insufficient performance with clinical samples. Multiplexing and high-throughput capacities are important for central laboratories, but most healthcare settings process only few samples per time. POCT use rules out expensive devices, systems requiring demanding sample preparation, and systems requiring standard microbiology laboratory facilities. NAAT serves well for the identification of viral and bacterial pathogens, and in some cases provides also the detection of AR genes. However, the commercial multiplexed diagnostic NAAT panels are far too expensive for routine diagnostics. Immunochromatographic tests, especially dip-sticks, are a low-cost and handy option for virus diagnostics and detection of inflammatory factors. Unfortunately systems capable of detection of antibiotic resistance proteins directly from clinical samples without enrichment cultures, culture isolation or sample purification do not yet exist. The routine diagnostic tools for infectious diseases should serve a wide field of requirements: both the identification of the pathogen (viral and bacterial), the detection of antibiotic resistance and the determination of the correct antibiotic dosing. Systems based on microscopy are not compatible with the detection of viruses or inflammatory factors. Diagnostic systems differ very much in their potential to provide all relevant data for medication (Table 1). Multiplexing NAAT-based systems can seamlessly incorporate the detection of emerging resistance-related genes or mutations. However, every update for a diagnostic panel requires new validations.
While central laboratories have resources to validate new tests against the standardized tests, smaller healthcare units are bound to use tests validated by authorities such as the FDA. The few systems currently capable of providing simultaneous ID and growth-based AST directly from clinical samples are based either on FISH (Accelerate Pheno), immunodiagnostics (e.g., mariAST, MultiPath, immunobiosensors), or digital AST (dAST) (Table 1). As their properties and application areas differ, all these systems may have a good future. Rapid growth-based diagnostic systems rely on accelerated cultivations. For this reason, it is necessary to validate every new technology carefully against the standard tests accepted by EUCAST and CLSI. The MIC breakpoints (sensitive, resistant, or in-between) must be re-defined for each system and each tested organism. This requirement definitely retards the deployment of new technologies. While most novel AST systems only perform an endpoint analysis, the systems based on microscopy, heat production, movements, immunodetection or detection of mass changes in principle facilitate on-line monitoring. Biosensor-based AST systems, however, yet miss convincing clinical demonstrations.

In practice clinical diagnosis should be obtained during office hours, meaning $<8 \mathrm{~h}$ from sampling to results. This does not leave time for enrichment cultivations or preparation of culture isolates. The strategy "take a sample, store and analyze later" works fine for diagnosis of slowly advancing infections, but also for NAAT-based systems which do not require viable microbes. Growth-based AST, on the other hand, need fresh samples to ensure pathogen survival until the point of analysis.

Regarding the speed and the need to handle clinical polybacterial samples, the immunodiagnostic TPX-technology (ArcDia Ltd), growth-based FISH (Accelerate Pheno), the Multipath digital imaging technology based on nanoparticles for labeling and magnetic beads for capturing (First Light Diagnostics Inc.), and the NAAT-based dAST (Talis Inc.) seem promising options for rapid point-of-care testing of antimicrobial susceptibility. The Talis system is, however, not yet on the market. Immunobiosensors are still in their infancy, but may in the future become important in testing non-culturable microbes. Lateral Flow (immuno-chromatographic "dip-sticks") systems would be an ideal product format for clinical work, but their applicability has been so far proven only with isolated cultures (i.e., colonies on plate).

Due to the plethora of different resistance mechanisms, NAAT struggles with the detection of antibiotic resistances in Gramnegative bacteria (Maurer et al., 2017) and with the analysis of samples containing commensal flora. NAAT may fail to identify several ESBL genes and genes providing fluoroquinolone or aminoglycoside resistance. NAAT is, however, a powerful and necessary technology for the detection of fastidious, slowgrowing or intracellular pathogens, toxin-producing bacteria such as E. coli O157:H7, and viruses (Miller et al., 2018). Still, the increased use of NAAT has raised a concern about the fate of bacterial samples required for further studies (Marder et al., 2017; McAdam, 2017). Since NAAT does not require viable samples, subsequent epidemiologic studies or cultivation-based confirmatory AST may be impossible with the stored samples. Whole genome sequencing (WGS) is still in its infancy regarding 
TABLE 1 | Properties of technologies applicable to rapid identification and AST.

\begin{tabular}{|c|c|c|c|c|c|c|c|c|c|c|c|}
\hline Technology & $\begin{array}{l}\text { Company or } \\
\text { product } \\
\text { (examples) }\end{array}$ & Time for AST (h) & $\begin{array}{l}\text { Simultaneous ID } \\
\text { and AST }\end{array}$ & $\begin{array}{l}\text { Clinical } \\
\text { polymicrob. } \\
\text { samples }\end{array}$ & Online AST & $\begin{array}{l}\text { Provides } \\
\text { MICs }\end{array}$ & $\begin{array}{l}\text { Detects new } \\
\text { resistances }\end{array}$ & $\begin{array}{l}\text { AST for non- } \\
\text { culturable } \\
\text { microbes }\end{array}$ & $\begin{array}{l}\text { Enables } \\
\text { virus ID }\end{array}$ & $\begin{array}{l}\text { Level of } \\
\text { commercialization }\end{array}$ & References \\
\hline \multicolumn{12}{|c|}{ Standard cultivation tests } \\
\hline Broth dilution test & Several & $18-36$ & - & - & $\checkmark$ & $\checkmark$ & $\checkmark$ & - & - & Gold standard & \\
\hline $\begin{array}{l}\text { Disk diffusion test and } \\
\text { E-test }\end{array}$ & Several & $18-24$ & - & - & $\checkmark$ & $\checkmark$ & $\checkmark$ & - & - & Gold standard & \\
\hline \multicolumn{12}{|c|}{ Automated readers for cards or microtiter plates } \\
\hline $\begin{array}{l}\text { Broth } \\
\text { microdilution-based } \\
\text { instruments }\end{array}$ & $\begin{array}{l}\text { bioMerieux, BD, } \\
\text { Siemens }\end{array}$ & $5-16 h$ & - & - & $\checkmark$ & $\checkmark$ & $\checkmark$ & - & - & Commercial & \\
\hline $\begin{array}{l}\text { Disk diffusion-based } \\
\text { instruments }\end{array}$ & $\begin{array}{l}\text { Giles Scientific, } \\
\text { Oriana, BioRad, } \\
\text { BD }\end{array}$ & $5-16 h$ & - & - & $\checkmark$ & $\checkmark$ & $\checkmark$ & - & - & Commercial & \\
\hline \multicolumn{12}{|c|}{ Mass spectrometry (biochemical profiling, follow-up of antibiotic degradation, detection of anti-microbial protein) } \\
\hline $\begin{array}{l}\text { MALDI-TOF (Bruker } \\
\text { MBT) }\end{array}$ & $\begin{array}{l}\text { Bruker, Shimadzu, } \\
\text { Sciex, Waters }\end{array}$ & $2-4 \mathrm{~h}$ & - & - & - & - & $\checkmark$ & - & - & Commercial & \\
\hline $\begin{array}{l}\text { MBT-ASTRA (biochem. } \\
\text { profiling after antibiotic } \\
\text { exposure) }\end{array}$ & $\begin{array}{l}\text { Bruker Daltonik } \\
\text { GmbH }\end{array}$ & $2-4 \mathrm{~h}$ & - & - & - & $\checkmark$ & $\checkmark$ & - & - & Commercial & $\begin{array}{l}\text { Sparbier et al., } \\
2016\end{array}$ \\
\hline $\begin{array}{l}\text { Direct-On-Target } \\
\text { Microbial Growth Assay } \\
\text { (DOT-MGA) }\end{array}$ & $\begin{array}{l}\text { All instrument } \\
\text { providers }\end{array}$ & $4 \mathrm{~h}$ & - & - & - & $\checkmark$ & $\checkmark$ & - & - & Experimental & $\begin{array}{l}\text { Idelevich et al., } \\
\text { 2018; } \\
\text { Correa-Martínez } \\
\text { et al., } 2019\end{array}$ \\
\hline \multicolumn{12}{|c|}{ Fluorescence \& hybridization } \\
\hline $\begin{array}{l}\text { FISH (fluorescent } \\
\text { probes, microscope) }\end{array}$ & XpressFISH & $2-4 \mathrm{~h}$ & $\checkmark$ & $\checkmark$ & - & - & $\checkmark$ & - & - & Commercial & $\begin{array}{l}\text { Salimnia et al., } \\
2014\end{array}$ \\
\hline $\begin{array}{l}\text { Multiplexed automated } \\
\text { microscopy/FISH }\end{array}$ & $\begin{array}{l}\text { Accelerate } \\
\text { Diagnostics }\end{array}$ & $6.5 \mathrm{~h}$ & $\checkmark$ & $\checkmark$ & $\checkmark(\mathrm{fs})$ & $\checkmark$ & $\checkmark$ & - & - & Commercial & Hill et al., 2017 \\
\hline $\begin{array}{l}\text { Automated } \\
\text { fluorescence detection } \\
\text { for expression profiling }\end{array}$ & $\begin{array}{l}\text { NanoString } \\
\text { Technologies }\end{array}$ & $24 \mathrm{~h}$ & $\checkmark$ & $\checkmark$ & $\checkmark(\mathrm{fs})$ & $\checkmark$ & $\checkmark$ & - & $\checkmark$ & $\begin{array}{l}\text { Commercial, under } \\
\text { testing }\end{array}$ & $\begin{array}{l}\text { Barczak et al., } \\
\text { 2012; } \\
\text { Bhattacharyya } \\
\text { et al., 2017, 2019; } \\
\text { Kelley, 2017; } \\
\text { Koehler et al., } \\
2018\end{array}$ \\
\hline $\begin{array}{l}\text { Non-microscopic } \\
\text { imaging, fluorescent } \\
\text { antibody-bound } \\
\text { nanoparticles, } \\
\text { magnetic beads for } \\
\text { concentrating }\end{array}$ & $\begin{array}{l}\text { First Light } \\
\text { Diagnostics }\end{array}$ & $4 \mathrm{~h}$ & $\checkmark$ & $\checkmark$ & $\checkmark$ & $\checkmark$ & $\checkmark$ & - & $\checkmark$ & $\begin{array}{l}\text { Commercial, under } \\
\text { testing }\end{array}$ & $\begin{array}{l}\text { https://www. } \\
\text { firstlightdx.com/ } \\
\text { publications/ }\end{array}$ \\
\hline
\end{tabular}


TABLE 1 | Continued

\begin{tabular}{|c|c|c|c|c|c|c|c|c|c|c|c|}
\hline Technology & $\begin{array}{l}\text { Company or } \\
\text { product } \\
\text { (examples) }\end{array}$ & Time for AST (h) & $\begin{array}{l}\text { Simultaneous ID } \\
\text { and AST }\end{array}$ & $\begin{array}{l}\text { Clinical } \\
\text { polymicrob. } \\
\text { samples }\end{array}$ & Online AST & $\begin{array}{l}\text { Provides } \\
\text { MICs }\end{array}$ & $\begin{array}{l}\text { Detects new } \\
\text { resistances }\end{array}$ & $\begin{array}{l}\text { AST for non- } \\
\text { culturable } \\
\text { microbes }\end{array}$ & $\begin{array}{l}\text { Enables } \\
\text { virus ID }\end{array}$ & $\begin{array}{l}\text { Level of } \\
\text { commercialization }\end{array}$ & References \\
\hline \multicolumn{12}{|c|}{ Other imaging or spectroscopy-based systems } \\
\hline $\begin{array}{l}\text { Surface plasmon } \\
\text { resonance (SPR) }\end{array}$ & $\begin{array}{l}\text { Biacore } 3000 \text { and } \\
\text { exp. devices }\end{array}$ & $0.5-4 h$ & - & - & $\checkmark$ & $\checkmark$ & $\checkmark$ & $\checkmark$ & - & Experimental & $\begin{array}{l}\text { Chen et al., 2011; } \\
\text { Tao and Syal, } \\
2016\end{array}$ \\
\hline $\begin{array}{l}\text { Raman spectroscopy } \\
\text { (SERS) }\end{array}$ & Several & $2 \mathrm{~h}$ & $\checkmark$ & - & $\checkmark$ & $\checkmark$ & $\checkmark$ & - & - & Experimental & $\begin{array}{l}\text { Liu et al., 2016; } \\
\text { Wang et al., } 2018\end{array}$ \\
\hline $\begin{array}{l}\text { Smartphone-based } \\
\text { growth monitoring of } \\
\text { microplates, capillaries } \\
\text { or chips }\end{array}$ & Experimental & $2-4 \mathrm{~h}$ & - & - & $\checkmark$ & $\checkmark$ & $\checkmark$ & - & - & Experimental & $\begin{array}{l}\text { Kadlec et al., } \\
\text { 2014; Feng et al., } \\
\text { 2016; Cui et al., } \\
2018\end{array}$ \\
\hline \multicolumn{12}{|c|}{ Cell sorting systems, flow cytometry } \\
\hline Flow cytometry & FASTinov & $2 \mathrm{~h}$ & - & $\checkmark$ & $\checkmark$ & $\checkmark$ & $\checkmark$ & $(\checkmark)$ & - & Commercial & $\begin{array}{l}\text { Costa-de-Oliveira } \\
\text { et al., } 2017\end{array}$ \\
\hline \multicolumn{12}{|c|}{ Sensor-based detection of micromotions or mass changes } \\
\hline $\begin{array}{l}\text { Plasmonic imaging and } \\
\text { tracking for } \\
\text { nanomotions }\end{array}$ & Experimental & $<1 \mathrm{~h}$ & - & - & $\checkmark$ & $\checkmark$ & $\checkmark$ & $\checkmark$ & - & Experimental & Syal et al., 2016 \\
\hline $\begin{array}{l}\text { Atomic force } \\
\text { microscopy cantilever }\end{array}$ & Experimental & $0.25-4 h$ & - & - & $\checkmark$ & $(\checkmark)$ & $\checkmark$ & $(\checkmark)$ & - & Inverted microscope & Longo et al., 2013 \\
\hline $\begin{array}{l}\text { SAW and other mass } \\
\text { sensitive biosensors }\end{array}$ & Experimental & $0.5-6 h$ & - & - & $\checkmark$ & $(\checkmark)$ & $\checkmark$ & $(\checkmark)$ & $\checkmark$ & Experimental & $\begin{array}{l}\text { Chang et al., } \\
\text { 2007; Hoß and } \\
\text { Bendas, } 2017\end{array}$ \\
\hline \multicolumn{12}{|l|}{ Heat production } \\
\hline Microcalorimetry & $\begin{array}{l}\text { SymCel AB, TA } \\
\text { Instruments }\end{array}$ & Few hours & - & - & $\checkmark$ & $(\checkmark)$ & $\checkmark$ & $(\checkmark)$ & - & Commercial & $\begin{array}{l}\text { https://www. } \\
\text { laboratoryequipment } \\
\text { com/article/2017/ } \\
\text { 11/how-use- } \\
\text { calorimetry-tackle- } \\
\text { antibiotic- } \\
\text { resistance }\end{array}$ \\
\hline \multicolumn{12}{|c|}{ Immunochromatography (lateral flow tests, "dip-sticks") } \\
\hline $\begin{array}{l}\text { Resistance factor } \\
\text { specific binders }\end{array}$ & Coris Bioconcept & $0.25-4$ & - & - & - & - & - & - & - & Commercial & $\begin{array}{l}\text { ECCMID } 2015 \\
\text { Booth \#243 }\end{array}$ \\
\hline \multicolumn{12}{|c|}{ Immunodetection, fluorescence-based } \\
\hline $\begin{array}{l}\text { Two-photon } \\
\text { fluorescence } \\
\text { microscopy TPX }\end{array}$ & ArcDia & $2-4 \mathrm{~h}$ & $\checkmark$ & $\checkmark$ & $\checkmark$ & $\checkmark$ & $\checkmark$ & - & $\checkmark$ & $\begin{array}{l}\text { Commercial, under } \\
\text { testing }\end{array}$ & Koskinen, 2008 \\
\hline
\end{tabular}


TABLE 1 | Continued

\begin{tabular}{|c|c|c|c|c|c|c|c|c|c|c|c|}
\hline Technology & $\begin{array}{l}\text { Company or } \\
\text { product } \\
\text { (examples) }\end{array}$ & Time for AST (h) & $\begin{array}{l}\text { Simultaneous ID } \\
\text { and AST }\end{array}$ & $\begin{array}{l}\text { Clinical } \\
\text { polymicrob. } \\
\text { samples }\end{array}$ & Online AST & $\begin{array}{l}\text { Provides } \\
\text { MICs }\end{array}$ & $\begin{array}{l}\text { Detects new } \\
\text { resistances }\end{array}$ & $\begin{array}{l}\text { AST for non- } \\
\text { culturable } \\
\text { microbes }\end{array}$ & $\begin{array}{c}\text { - Enables } \\
\text { virus ID }\end{array}$ & $\begin{array}{l}\text { Level of } \\
\text { commercialization }\end{array}$ & References \\
\hline $\begin{array}{l}\text { Multipath (magnetic } \\
\text { beads, } \\
\text { non-microscopy } \\
\text { imaging) }\end{array}$ & $\begin{array}{l}\text { First Light } \\
\text { Diagnostics }\end{array}$ & $2-4 \mathrm{~h}$ & $\checkmark$ & $\checkmark$ & $\checkmark$ & $\checkmark$ & $\checkmark$ & - & $\checkmark$ & $\begin{array}{l}\text { Commercial, under } \\
\text { testing }\end{array}$ & \\
\hline \multicolumn{12}{|c|}{ Electrochemical biosensors or detection of volatile organic compounds } \\
\hline $\begin{array}{l}\text { rRNA-hybridization, } \\
\text { peroxidase signaling }\end{array}$ & GeneFluidics & $2-5 \mathrm{~h}$ & $\checkmark$ & $\checkmark$ & - & $\checkmark$ & $\checkmark$ & $(\checkmark)$ & - & Commercial & $\begin{array}{l}\text { Mach et al., 2011; } \\
\text { Liu et al., } 2014\end{array}$ \\
\hline $\begin{array}{l}\text { Colorimetric sensor } \\
\text { array for VOC detection }\end{array}$ & $\begin{array}{l}\text { Specific } \\
\text { Diagnostics }\end{array}$ & $3-4 \mathrm{~h}$ & $\checkmark$ & - & $\checkmark$ & $\checkmark$ & $\checkmark$ & - & - & Commercial & $\begin{array}{l}\text { https://www. } \\
\text { specific-dx.com/ } \\
\text { reveal-ast }\end{array}$ \\
\hline $\begin{array}{l}\text { Redox-indicator } \\
\text { resazurin }\end{array}$ & Experimental & $1 \mathrm{~h}$ & - & - & $\checkmark$ & $\checkmark$ & $\checkmark$ & $(\checkmark)$ & - & Experimental & $\begin{array}{l}\text { Besant et al., } \\
\text { 2015; Avesar } \\
\text { et al., } 2017\end{array}$ \\
\hline $\begin{array}{l}\text { Field effect enzymatic } \\
\text { immunosensor }\end{array}$ & Experimental & $1-2 \mathrm{~h}$ & $\checkmark$ & $\checkmark$ & $\checkmark$ & $\checkmark$ & $\checkmark$ & $(\checkmark)$ & - & Experimental & Shi et al., 2018 \\
\hline $\begin{array}{l}\text { Electronic nose: ion } \\
\text { mobility spectrometry } \\
\text { sensor }\end{array}$ & $\begin{array}{l}\text { Environics, } \\
\text { Olfactomics }\end{array}$ & Few minutes & $(\checkmark)$ & - & $(\checkmark)$ & - & - & - & - & Commercial & $\begin{array}{l}\text { Lewis et al., 2017; } \\
\text { Saviauk et al., } \\
2018\end{array}$ \\
\hline \multicolumn{12}{|l|}{ NAAT } \\
\hline PCR, qPCR & Several & $2-4 \mathrm{~h}$ & $\checkmark$ & $\checkmark$ & - & - & - & $\checkmark$ & $\checkmark$ & Commercial & \\
\hline $\begin{array}{l}\text { Integrated } \\
\text { cassette-based NAAT } \\
\text { solutions }\end{array}$ & Several & $4 \mathrm{~h}$ & $\checkmark$ & $\checkmark$ & - & - & - & $\checkmark$ & $\checkmark$ & Commercial & \\
\hline Isothermal amplification & Several & $0.5-4$ & $\checkmark$ & $\checkmark$ & - & - & - & $\checkmark$ & $\checkmark$ & Commercial & \\
\hline $\begin{array}{l}\text { Whole Genome } \\
\text { Sequencing }\end{array}$ & Several & $1-24 \mathrm{~h}$ & $\checkmark$ & $\checkmark$ & - & - & $\checkmark$ & $\checkmark$ & $\checkmark$ & Commercial & \\
\hline \multicolumn{12}{|c|}{ NAAT combined to cultivation } \\
\hline $\begin{array}{l}\text { Isothermal } \\
\text { amplification, digital } \\
\text { AST }\end{array}$ & Talis Biomedical & $0.5 \mathrm{~h}$ & $\checkmark$ & $\checkmark$ & $\checkmark(\mathrm{fs})$ & $\checkmark$ & $\checkmark$ & $(\checkmark)$ & $\checkmark$ & $\begin{array}{l}\text { Under } \\
\text { commercialization }\end{array}$ & $\begin{array}{l}\text { Schoepp et al., } \\
\text { 2017, 2020; } \\
\text { https://talis.bio }\end{array}$ \\
\hline
\end{tabular}

The marking $\checkmark$ is in brackets, if the possible feature lacks experimental demonstrations. - indicates a missing property. fr indicates the need for frequent sampling. 
TABLE 2 | Contemplation on Prof. Kahlmeter's criteria for new technologies (Kahlmeter, 2016).

\begin{tabular}{ll}
\hline Criteria Contemplation &
\end{tabular}

Generally applicable or restricted to certain infections?

Capacity: how many organisms/agents per hour can be processed

Has the technology been validated against reference methods?

Are there any reference installations?

Is scientific literature available?

When on market?
In principle all growth-based rapid AST systems are generic and work with culture isolates. However, for polymicrobial clinical samples they must be coupled with specific probes or antibodies which provide ID. Therefore, specific test panels have been developed e.g., for respiratory, urinary, and blood samples. The pathogen load may not be high enough for direct analysis, and especially blood samples may require culturing prior to analysis. AST for fastidious, non-culturable, or intracellular pathogens call for NAAT. The complexity of the sample matrix affects the choice of the diagnostic system and the methods for sample preparations.

DNA-arrays and PCR systems (including multiplexed cassette designs) have a high throughput capacity. Mass-spectrometry performed on PCR products can handle hundreds of samples per hour in central laboratories. In outpatient clinics speed is more essential than the capacity. High multiplexing (parameters per sample) and high-throughput capacity (number of samples) may be challenging to combine. Progress in NAAT, immunodiagnostics, biosensor technologies and microfluidics has yielded several systems capable of analyzing tens of samples per day or even during a single work shift.

So far quite few quick technologies have received FDA-approval. Currently they include PCR-tests, cartridge-based NAAT-systems and Accelerate Pheno (automated microscopy). Several clinical trials are in progress to achieve CE-marking or FDA-clearance.

Commercial analysis systems in general do have, and manufacturers tend to publish successful clinical trials. However, finding a lab which lines up to the specific needs may be challenging.

For mature commercial systems scientific references can be fairly easily found. For near-market products this is much more challenging. Companies often only declare on-going tests, but provide only limited info about the progress. Scientific articles typically present proof-of-concept level data obtained with isolated cultures spiked into sample matrices.

Many systems are already available, but they may have a limited scope for ID/AST. Due to lack of clinical data, some systems have a "research use only" status. Some have been accepted only for veterinary use. Commercially mature products include several NAAT systems, FISH-systems and immunodiagnostic system. its use for rapid AST. The required bioinformatics is challenging, and universal open databases are needed to interpret the results.

In the near future, the progress in chip, microfluidics and biosensor technologies may provide new inexpensive AST systems. Integration of many sophisticated technologies will be needed to resolve problems with a low initial pathogen number and the presence of contaminating sample matrices. Several scientific publications have already demonstrated the successful use of smartphone optics and telecommunication capacity for monitoring of microwell or microcapillary cultivations, $\mathrm{pH}$ and redox changes and for delivering the read-outs of biosensor data (Berg et al., 2015; Feng et al., 2016; Cui et al., 2018; HernándezNeuta et al., 2019). The obvious lack of IPR protection for smartphone-based analytic devices and the requirement to validate analytic devices as an entity unfortunately discourages commercialization of these technologies.

\section{CONCLUSIONS}

Standard growth-based technologies based on disc diffusion and broth dilution still dominate in AST. They are slow and require pure cultures, but in other aspects serve the purpose well. Only few rapid growth-based AST methods work directly with polymicrobial clinical samples, which is required in POCT.
Sensitive growth monitoring can be achieved either by frequent sampling (applicable to disruptive methods like FISH or NAAT) or by on-line immunodiagnostic methods. dAST with chipbased microfluidics devices and isothermal amplification can potentially revolutionize phenotypic AST. With this approach, thousands of individual single bacterium droplet samples can be categorized according whether the amount of amplified DNA reaches the limit defined for growing cells. The FISH-based Accelerate Pheno system has already reached FDA approval. The mariPOC device based on immunodetection with twophoton excitation fluoroscopy allows non-disruptive microbial identification. Its clinical validation for AST should be followed with interest, as this technology enables the use of nonpurified clinical samples and also allows follow-up studies to confirm the results. Additionally it already provides a rapid and sensitive identification of both bacterial and viral pathogens. The Multipath technology (First Light Diagnostics Inc.) may provide a functional platform for automated on-line detection by applying fluorescent nanoparticles for signaling, magnetic beads for binding, and non-microscopic imaging for detection. Multiplexing cartridge-based NAAT solutions are likely to reach a significant customer base in central laboratories, since they offer high speed, work well with non-culturable bacteria and viruses and possess an excellent high-throughput power for pathogen 
ID. However, all new emerging technologies struggle to meet all of the criteria Prof. Kahlmeter set for AST technologies (Table 2). As none of the presented technologies is optimal in all aspects, it is probable that many of them will reach a large customer base. Therefore the consensus statement of the PIAMR AMR- RDT Working Group on Antimicrobial Resistance and Rapid Diagnostic Testing is still valid: "There is no single major, or broadly accepted, technological breakthrough that leads the field of rapid AST platform development" (van Belkum et al., 2019b).

\section{AUTHOR'S NOTE}

The described technologies have been taken into consideration without any pre-selection and have been judged only by their applicability to clinical diagnostics.

\section{AUTHOR CONTRIBUTIONS}

$\mathrm{AV}$ was the main responsible for the acquisition and structuring of the scientific literature. The text and conclusions were

\section{REFERENCES}

Almeida, C., Azevedo, N. F., Iversen, C., Fanning, S., Keevil, C. W., and Vieira, M. J. (2009). Development and application of a novel peptide nucleic acid probe for the specific detection of cronobacter genomospecies (Enterobacter sakazakii) in powdered infant formula. Appl. Environ. Microbiol. 75, 2925-2930. doi: 10.1128/AEM.02 470-08

ARUP (2020). Scientific Resource for Research, and Education: Educational Resources - Rapid Antimicrobial Susceptibility Testing | University of Utah. Available online at: https://arup.utah.edu/education/fisher-rapidAST-2019. php/ (accessed May 2, 2020).

Athamanolap, P., Hsieh, K., Chen, L., Yang, S., and Wang, T.-H. (2017). Integrated bacterial identification and antimicrobial susceptibility testing using per and high-resolution melt. Anal. Chem. 89, 11529-11536. doi: 10.1021/acs.analchem.7b02809

Avesar, J., Rosenfeld, D., Truman-Rosentsvit, M., Ben-Arye, T., Geffen, Y., Bercovici, M., et al. (2017). Rapid phenotypic antimicrobial susceptibility testing using nanoliter arrays. PNAS. 114, E5787-E5795. doi: $10.1073 /$ pnas. 1703736114

Baeza, L. L., Pfennigwerth, N., Greissl, C., Göttig, S., Saleh, A., Stelzer, Y., et al. (2019). Comparison of five methods for detection of carbapenemases in enterobacterales with proposal of a new algorithm. Clin. Microbiol. Infect. 25, 1286.e9-1286.e15. doi: 10.1016/j.cmi.2019.03.003

Barany, F. (1991). Genetic disease detection and DNA amplification using cloned thermostable ligase. Proc. Natl. Acad. Sci. U.S.A. 88, 189-93. doi: 10.1073/pnas.88.1.189

Barczak, A. K., Gomez, J. E., Kaufmann, B. B., Hinson, E. R., Cosimi, L., Borowsky, M. L., et al. (2012). RNA signatures allow rapid identification of pathogens and antibiotic susceptibilities. PNAS. 109, 6217-6222. doi: 10.1073/pnas.1119540109

Barnes, L., Heithoff, D. M., Mahan, S. P., Fox, G. N., Zambrano, A., Choe, J., et al. (2018). Smartphone-based pathogen diagnosis in urinary sepsis patients. EBioMedicine 36, 73-82. doi: 10.1016/j.ebiom.2018. 09.001

Berg, B., Cortazar, B., Tseng, D., Ozkan, H., Feng, S., Wei, Q., et al. (2015). Cellphone-based hand-held microplate reader for point-of-care testing of enzyme-linked immunosorbent assays. ACS Nano 9, 7857-7866. doi: 10.1021 /acsnano.5b03203 processed by all the authors. VH and OL mediated valuable contacts to the expert biotech scientists and healthcare experts consulted for this review. All authors contributed to the writing and accepted the final version.

\section{FUNDING}

This work was supported by the Business Finland project DARE (Dnro 2769/31/2018), which evaluated the current and emerging technologies for AST and the possibilities to develop new innovative products for AST testing. The authors declare that this study received funding from Fimlab Laboratories. The funder was not involved in the study design, collection, analysis, interpretation of data, the writing of this article or the decision to submit it for publication.

\section{ACKNOWLEDGMENTS}

We thank to Dr. Pierre Bogaerts, who pointed out which practical issues are important in clinical diagnostics of microbial diseases.

Besant, J. D., Sargent, E. H., and Kelley, S. O. (2015). Rapid electrochemical phenotypic profiling of antibiotic-resistant bacteria. Lab. Chip. 15, 2799-2807. doi: 10.1039/C5LC00375J

Bhattacharyya, R., Liu, J., Ma, P., Bandyopadhyay, N., Livny, J., and Hung, D. (2017). Rapid phenotypic antibiotic susceptibility testing through RNA detection. Open Forum Infect. Dis. 4, S33-S33. doi: 10.1093/ofid/ofx162.082

Bhattacharyya, R. P., Bandyopadhyay, N., Ma, P., Son, S. S., Liu, J., He, L. L., et al. (2019). Simultaneous detection of genotype and phenotype enables rapid and accurate antibiotic susceptibility determination. Nat. Med. 25, 1858-1864. doi: 10.1038/s41591-019-0650-9

Boedicker, J. Q., Li, L., Kline, T. R., and Ismagilov, R. F. (2008). Detecting bacteria and determining their susceptibility to antibiotics by stochastic confinement in nanoliter droplets using plug-based microfluidics. Lab. Chip 8, 1265-1272. doi: 10.1039/b804911d

Bogaerts, P., de Castro, R. R., de Mendonça, R., Huang, T. D., Denis, O., and Glupczynski, Y. (2013). Validation of carbapenemase and extendedspectrum $\beta$-lactamase multiplex endpoint PCR assays according to ISO 15189. J. Antimicrob. Chemother. 68, 1576-1582. doi: 10.1093/jac/dkt065

Bogaerts, P., Yunus, S., Massart, M., Huang, T.-D., and Glupczynski, Y. (2016). Evaluation of the BYG carba test, a new electrochemical assay for rapid laboratory detection of carbapenemase-producing enterobacteriaceae. J. Clin. Microbiol. 54, 349-358. doi: 10.1128/JCM.02404-15

Bonkat, G., Braissant, O., Widmer, A. F., Frei, R., Rieken, M., Wyler, S., et al. (2012). Rapid detection of urinary tract pathogens using microcalorimetry: principle, technique and first results. BJU Int. 110, 892-897. doi: 10.1111/j.1464-410X.2011.10902.x

Boutal, H., Naas, T., Devilliers, K., Oueslati, S., Dortet, L., Bernabeu, S., et al. (2017). Development and validation of a lateral flow immunoassay for rapid detection of NDM-producing enterobacteriaceae. J. Clin. Microbiol. 55, 2018-2029. doi: 10.1128/JCM.00248-17

Boyle, D. (2017). Unitaid TB Diagnostics - NAAT for Microscopy Stations. Available online at: http://unitaid.org/assets/2017-Unitaid-TB-DiagnosticsTechnology-Landscape.pdf (accessed March 8, 2019).

Bruning, A. H. L., Aatola, H., Toivola, H., Ikonen, N., Savolainen-Kopra, C., Blomqvist, S., et al. (2018). Rapid detection and monitoring of human coronavirus infections. New Microbes and New Infect. 24, 52-55. doi: 10.1016/j.nmni.2018.04.007

Bugrysheva, J. V., Lascols, C., Sue, D., and Weigel, L. M. (2016). Rapid antimicrobial susceptibility testing of bacillus anthracis, yersinia pestis, and 
burkholderia pseudomallei by use of laser light scattering technology. J. Clin. Microbiol. 54, 1462-1471. doi: 10.1128/JCM.03251-15

Burg, T. P., Godin, M., Knudsen, S. M., Shen, W., Carlson, G., Foster, J. S., et al. (2007). Weighing of biomolecules, single cells and single nanoparticles in fluid. Nature 446, 1066-1069. doi: 10.1038/nature05741

Butini, M. E., Gonzalez Moreno, M., Czuban, M., Koliszak, A., Tkhilaishvili, T., Trampuz, A., et al. (2018). Real-time antimicrobial susceptibility assay of planktonic and biofilm bacteria by isothermal microcalorimetry. Adv. Exp. Med. Biol. 1214, 61-77. doi: 10.1007/5584_2018_291

Campbell, J., McBeth, C., Kalashnikov, M., Boardman, A. K., Sharon, A., and Sauer-Budge, A. F. (2016). Microfluidic advances in phenotypic antibiotic susceptibility testing. Biomed. Microdevices 18:103. doi: 10.1007/s10544-016-0121-8

Cassini, A., Högberg, L. D., Plachouras, D., Quattrocchi, A., Hoxha, A., Simonsen, G. S., et al. (2019). Attributable deaths and disability-adjusted life-years caused by infections with antibiotic-resistant bacteria in the EU and the European economic area in 2015: a population-level modelling analysis. Lancet. Infect. Dis. 19, 56-66. doi: 10.1016/S1473-3099(18)30 605-4

Centers for Disease Control and Prevention (2018). Be Antibiotics Aware: Smart Use, Best Care | Features | CDC. Available online at: https://www.cdc.gov/ features/antibioticuse/index.html (accessed May 28, 2019).

Cerqueira, L., Fernandes, R. M., Ferreira, R. M., Carneiro, F., Dinis-Ribeiro, M., Figueiredo, C., et al. (2011). PNA-FISH as a new diagnostic method for the determination of clarithromycin resistance of helicobacter pylori. BMC Microbiol. 11:101. doi: 10.1186/1471-2180-11-101

Ceyssens, P.-J., Soetaert, K., Timke, M., Van den Bossche, A., Sparbier, K., De Cremer, K., et al. (2017). Matrix-assisted laser desorption ionizationtime of flight mass spectrometry for combined species identification and drug sensitivity testing in mycobacteria. J. Clin. Microbiol. 55, 624-634. doi: 10.1128/JCM.02089-16

Chang, K.-S., Chang, C.-K., and Chen, C.-Y. (2007). A surface acoustic wave sensor modified from a wireless transmitter for the monitoring of the growth of bacteria. Sensors Actuat B-Chem. 125, 207-213. doi: 10.1016/j.snb.2007.02.007

Chantell, C. (2015). Multiplexed automated digital microscopy for rapid identification and antimicrobial susceptibility testing of bacteria and yeast directly from clinical samples. Clin. Microbiol. Newsl. 37, 161-167. doi: 10.1016/j.clinmicnews.2015.10.001

Charnot-Katsikas, A., Tesic, V., Love, N., Hill, B., Bethel, C., Boonlayangoor, S., et al. (2017). Use of the accelerate pheno system for identification and antimicrobial susceptibility testing of pathogens in positive blood cultures and impact on time to results and workflow. J. Clin. Microbiol. 56, e01166-17. doi: 10.1128/JCM.01166-17

Chen, H., Lin, C.-H., Su, C.-Y., Chen, H.-P., and Chiang, Y.-L. (2011). Surface Plasmon Resonance Biotechnology for Antimicrobial Susceptibility Test. Available online at: www.intechopen.com

Choi, J., Jeong, H. Y., Lee, G. Y., Han, S., Han, S., Jin, B., et al. (2017). Direct, rapid antimicrobial susceptibility test from positive blood cultures based on microscopic imaging analysis. Sci. Rep. 7:1148. doi: 10.1038/s41598-017-01278-2

Choi, J., Yoo, J., Lee, M., Kim, E.-G., Lee, J. S., Lee, S., et al. (2014). A rapid antimicrobial susceptibility test based on single-cell morphological analysis. Sci. Transl. Med. 6:267ra174. doi: 10.1126/scitranslmed.3009650

Compton, J. (1991). Nucleic acid sequence-based amplification. Nature 350, 91-92. doi: 10.1038/350091a0

Correa-Martínez, C. L., Idelevich, E. A., Sparbier, K., Kostrzewa, M., and Becker, K. (2019). Rapid detection of extended-spectrum $\beta$-lactamases (ESBL) and AmpC $\beta$-lactamases in enterobacterales: development of a screening panel using the MALDI-TOF MS-based direct-on-target microdroplet growth assay. Front. Microbiol. 10:13. doi: 10.3389/fmicb.2019.00013

Costa-de-Oliveira, S., Teixeira-Santos, R., Silva, A. P., Pinho, E., Mergulhão, P., Silva-Dias, A., et al. (2017). Potential impact of flow cytometry antimicrobial susceptibility testing on the clinical management of gramnegative bacteremia using the FASTinov® Kit. Front. Microbiol. 8:2455. doi: 10.3389/fmicb.2017.02455

Cui, X., Ren, L., Shan, Y., Wang, X., Yang, Z., Li, C., et al. (2018). Smartphone-based rapid quantification of viable bacteria by single-cell microdroplet turbidity imaging. Analyst 143, 3309-3316. doi: 10.1039/C8AN00456K
Curtis, K. A., Rudolph, D. L., and Owen, S. M. (2008). Rapid detection of HIV-1 by reverse-transcription, loop-mediated isothermal amplification (RT-LAMP). J. Virol. Methods 151, 264-270. doi: 10.1016/j.jviromet.2008. 04.011

Delport, J. A., Mohorovic, I., Burn, S., McCormick, J. K., Schaus, D., Lannigan, R., et al. (2016). Rapid detection of meticillin-resistant staphylococcus aureus bacteraemia using combined three-hour short-incubation matrixassisted laser desorption/ionization time-of-flight MS identification and alere culture colony PBP2a detection test. J. Med. Microbiol. 65, 626-631. doi: 10.1099/jmm.0.000285

den Hertog, A. L., Menting, S., Smienk, E. T., Werngren, J., Hoffner, S., and Anthony, R. M. (2014). Evaluation of a microcolony growth monitoring method for the rapid determination of ethambutol resistance in Mycobacterium tuberculosis. BMC Infect. Dis. 14:380. doi: $10.1186 / 1471-2334-14-380$

Descours, G., Desmurs, L., Hoang, T. L. T., Ibranosyan, M., Baume, M., Ranc, A. G., et al. (2018). Evaluation of the accelerate pheno ${ }^{\mathrm{TM}}$ system for rapid identification and antimicrobial susceptibility testing of Gram-negative bacteria in bloodstream infections. Eur. J. Clin. Microbiol. Infect. Dis. 37, 1573-1583. doi: 10.1007/s10096-018-3287-6

Doern, C. D. (2018). The slow march toward rapid phenotypic antimicrobial susceptibility testing: are we there yet? J. Clin. Microbiol. 56, e01999-17. doi: 10.1128/JCM.01999-17

Ellington, M. J., Ekelund, O., Aarestrup, F. M., Canton, R., Doumith, M., Giske, C., et al. (2017). The role of whole genome sequencing in antimicrobial susceptibility testing of bacteria: report from the EUCAST subcommittee. Clin. Microbiol. Infect. 23, 2-22. doi: 10.1016/j.cmi.2016.11.012

Enroth, H., Retz, K., Andersson, S., Andersson, C., Svensson, K., Ljungström, L., et al. (2019). Infectious diseases evaluation of QuickFISH and maldi sepsityper for identification of bacteria in bloodstream infection. Infect. Dis. 51, 249-258. doi: 10.1080/23744235.2018.1554258

Entenza, J. M., Bétrisey, B., Manuel, O., Giddey, M., Sakwinska, O., Laurent, F., et al. (2014). Rapid detection of staphylococcus aureus strains with reduced susceptibility to vancomycin by isothermal microcalorimetry. J. Clin. Microbiol. 52, 180-186. doi: 10.1128/JCM.01820-13

Etayash, H., Khan, M. F., Kaur, K., and Thundat, T. (2016). Microfluidic cantilever detects bacteria and measures their susceptibility to antibiotics in small confined volumes. Nat. Commun. 7, 1-9. doi: 10.1038/ncomms 12947

EU (2013). Commission Implementing Decision of, 12 November 2013 as Regards a Union Financial Aid Towards a Coordinated Control Plan for Antimicrobial Resistance Monitoring in Zoonotic Agents. Available online at: https://eur-lex. europa.eu/legal-content/EN/TXT/?uri=CELEX\%3A32013D0653

Feng, S., Tseng, D., Di Carlo, D., Garner, O. B., and Ozcan, A. (2016). High-throughput and automated diagnosis of antimicrobial resistance using a cost-effective cellphone-based micro-plate reader. Sci. Rep. 6:39203. doi: $10.1038 /$ srep39203

Francois, P., Tangomo, M., Hibbs, J., Bonetti, E.-J., Boehme, C. C., Notomi, T., et al. (2011). Robustness of a loop-mediated isothermal amplification reaction for diagnostic applications. FEMS Immunol. Med. Microbiol. 62, 41-48. doi: 10.1111/j.1574-695X.2011.00785.x

Fredborg, M., Rosenvinge, F. S., Spillum, E., Kroghsbo, S., Wang, M., and Sondergaard, T. E. (2015). Rapid antimicrobial susceptibility testing of clinical isolates by digital time-lapse microscopy. Eur. J. Clin. Microbiol. Infect. Dis. 34, 2385-2394. doi: 10.1007/s10096-015-2492-9

GeneFludics Inc. (n.d.). GeneFluidics Announces CE-IVD Marking of UtiMaxT ${ }^{T M}$ uropathogen Identification (ID) and Antimicrobial Susceptibility Testing (AST): GenefluidicsLifeScience. Available online at: http://www.genefluidics. com/genefluidics-announces-ce-ivd-marking-of-utimax-uropathogenidentification-id-and-antimicrobial-susceptibility-testing-ast/ (accessed August 18, 2019).

Glupczynski, Y., Jousset, A., Evrard, S., Bonnin, R. A., Huang, T.-D., Dortet, L., et al. (2017). Prospective evaluation of the OKN K-SeT assay, a new multiplex immunochromatographic test for the rapid detection of OXA-48like, KPC and NDM carbapenemases. J. Antimicrob. Chemother. 72, 1955-1960. doi: $10.1093 / \mathrm{jac} / \mathrm{dkx} 089$

Halford, C., Gonzalez, R., Campuzano, S., Hu, B., Babbitt, J. T., Liu, J., et al. (2013). Rapid antimicrobial susceptibility testing by sensitive detection of precursor 
rRNA using a novel electrochemical biosensing platform. Antimicrob. Agents Chemother. 57, 936-943. doi: 10.1128/AAC.00615-12

Harris, P. N. A., and Ferguson, J. K. (2012). Antibiotic therapy for inducible AmpC $\beta$-lactamase-producing Gram-negative bacilli: what are the alternatives to carbapenems, quinolones and aminoglycosides? Int. J. Antimicrob. Agents 40, 297-305. doi: 10.1016/j.ijantimicag.2012.06.004

Hassibi, A., Manickam, A., Singh, R., Bolouki, S., Sinha, R., Jirage, K. B., et al. (2018). Multiplexed identification, quantification and genotyping of infectious agents using a semiconductor biochip. Nat. Biotechnol. 36, 738-745. doi: $10.1038 /$ nbt.4179

Hayden, R. T., Clinton, L. K., Hewitt, C., Koyamatsu, T., Sun, Y., Jamison, G., et al. (2016). Rapid antimicrobial susceptibility testing using forward laser light scatter technology. J. Clin. Microbiol. 54, 2701-2706. doi: 10.1128/JCM.01475-16

He, J., Mu, X., Guo, Z., Hao, H., Zhang, C., Zhao, Z., et al. (2014). A novel microbead-based microfluidic device for rapid bacterial identification and antibiotic susceptibility testing. Eur. J. Clin. Microbiol. Infect. Dis. 33, 2223-2230. doi: 10.1007/s10096-014-2182-z

Hernández-Neuta, I., Neumann, F., Brightmeyer, J., Ba Tis, T., Madaboosi, N., Wei, Q., et al. (2019). Smartphone-based clinical diagnostics: towards democratization of evidence-based health care. J. Intern. Med. 285, 19-39. doi: 10.1111/joim. 12820

Hill, B., Beavis, K. G., Boonlayangoor, S., Tesic, V., Charnot-Katsikas, A., Bethel, C., et al. (2017). Use of the accelerate pheno system for identification and antimicrobial susceptibility testing of pathogens in positive blood cultures and impact on time to results and workflow. J. Clin. Microbiol. 56, 1-13. doi: $10.1128 / \mathrm{jcm} .01166-17$

Hong Nguyen, M., Clancy, C. J., William Pasculle, A., Pappas, P. G., Alangaden, G., Pankey, G. A., et al. (2019). Performance of the T2bacteria panel for diagnosing bloodstream infections. Ann. Intern. Med. 170, 845-852. doi: $10.7326 / \mathrm{M} 18-2772$

Hoß, S. G., and Bendas, G. (2017). "Mass-sensitive biosensor systems to determine the membrane interaction of analytes," in Methods in Molecular Biology. Vol. 1520. (Clifton, NJ), 145-157. doi: 10.1007/978-1-4939-6634-9_9

Howell, M., Wirz, D., Daniels, A. U., and Braissant, O. (2012). Application of a microcalorimetric method for determining drug susceptibility in mycobacterium species. J. Clin. Microbiol. 50, 16-20. doi: 10.1128/JCM.05556-11

Huang, T.-H., Ning, X., Wang, X., Murthy, N., Tzeng, Y.-L., and Dickson, R. M. (2015). Rapid cytometric antibiotic susceptibility testing utilizing adaptive multidimensional statistical metrics. Anal. Chem. 87, 1941-1949. doi: $10.1021 /$ ac504241x

Hughes, M. D. (2018). Advances and Trends in Sepsis Diagnostics. Available online at: www.eacorp.com (Accessed March 12, 2019).

Idelevich, E. A., Schüle, I., Grünastel, B., Wüllenweber, J., Peters, G., and Becker, K. (2014). Rapid identification of microorganisms from positive blood cultures by MALDI-TOF mass spectrometry subsequent to very shortterm incubation on solid medium. Clin. Microbiol. Infect. 20, 1001-1006. doi: 10.1111/1469-0691.12640

Idelevich, E. A., Storck, L. M., Sparbier, K., Drews, O., Kostrzewa, M., and Becker, K. (2018). Rapid direct susceptibility testing from positive blood cultures by the matrix-assisted laser desorption ionization-time of flight mass spectrometrybased direct-on-target microdroplet growth assay. J. Clin. Microbiol. 56, 00913-00918. doi: 10.1128/JCM.00913-18

Jacoby, G. A. (2009). AmpC -Lactamases. Clin. Microbiol. Rev. 22, 161-182. doi: 10.1128/CMR.00036-08

Kadlec, M. W., You, D., Liao, J. C., and Wong, P. K. (2014). A cell phone-based microphotometric system for rapid antimicrobial susceptibility testing. J. Lab. Autom. 19, 258-266. doi: 10.1177/2211068213491095

Kahlmeter, G. (2014). Defining antibiotic resistance-towards international harmonization. Ups. J. Med. Sci. 119, 78-86. doi: 10.3109/03009734.2014.901446

Kahlmeter, G. (2016). Rapid Phenotypic Susceptibility Testing. in Symposium Lecture in Session: New and Rapid Detection of Antimicrobial Resistance. ECCMID Symposium 2016 on Bacterial Susceptibility \& Resistance. Amsterdam, The Netherlands. Available online at: https://www.escmid.org/escmid_ publications/escmid_elibrary/material/?mid=33585
Kang, D.-K., Ali, M. M., Zhang, K., Huang, S. S., Peterson, E., Digman, M. A., et al. (2014). ARTICLE Rapid detection of single bacteria in unprocessed blood using integrated comprehensive droplet digital detection. Nat. Commun. 5:5427. doi: $10.1038 /$ ncomms6427

Kang, W., Sarkar, S., Lin, Z. S., McKenney, S., and Konry, T. (2019). Ultrafast parallelized microfluidic platform for antimicrobial susceptibility testing of gram positive and negative bacteria. Anal. Chem. 91, 6242-6249. doi: 10.1021/acs.analchem.9b00939

Kelley, S. O. (2017). New technologies for rapid bacterial identification and antibiotic resistance profiling. SLAS TECHNOLOGY: Translating Life Sciences Innovation 22, 113-121. doi: 10.1177/2211068216680207

Kinnunen, P., Sinn, I., McNaughton, B. H., Newton, D. W., Burns, M. A., and Kopelman, R. (2011). Monitoring the growth and drug susceptibility of individual bacteria using asynchronous magnetic bead rotation sensors. Biosens. Bioelectron. 26, 2751-2755. doi: 10.1016/j.bios.2010.10.010

Kitao, T., Miyoshi-Akiyama, T., Shimada, K., Tanaka, M., Narahara, K., Saito, N., et al. (2010). Development of an immunochromatographic assay for the rapid detection of $\mathrm{AAC}\left(6^{\prime}\right)$-Iae-producing multidrug-resistant Pseudomonas aeruginosa. J. Antimicrob. Chemother. 65, 1382-1386. doi: 10.1093/jac/dkq148

Koehler, J. W., Douglas, C. E., and Minogue, T. D. (2018). A highy multiplexed broad pathogen detection assay for infectious disease diagnostics. PLOS Negl. Trop. Dis. 12:e0006889. doi: 10.1371/journal.pntd.0006889

Koskinen, J. O. (2008). Two-Photon Excitation Fluorometry in Detection (Issue January).

Lai, S. Y., Deffenderfer, O. F., Hanson, W., Phillips, M. P., and Thaler, E. R. (2002). Identification of upper respiratory bacterial pathogens with the electronic nose. Laryngoscope 112, 975-979. doi: 10.1097/00005537-200206000-00007

Leclercq, R., Cantón, R., Brown, D. F. J., Giske, C. G., Heisig, P., Macgowan, A. P., et al. (2013). EUCAST expert rules in antimicrobial susceptibility testing. Clin. Microbiol. Infect. 19, 141-160. doi: 10.1111/j.1469-0691.2011.03703.x

Leclercq, R., and Courvalin, P. (2002). Resistance to macrolides and related antibiotics in Streptococcus pneumoniae. Antimicrob. Agents Chemother. 46, 2727-34. doi: 10.1128/AAC.46.9.2727-2734.2002

Lee, D., Kim, E. J., Kilgore, P. E., Kim, S. A., Takahashi, H., Ohnishi, M., et al. (2015). Clinical evaluation of a loop-mediated isothermal amplification (LAMP) assay for rapid detection of neisseria meningitidis in cerebrospinal fluid. PLoS ONE 10:e0122922. doi: 10.1371/journal.pone.01 22922

Lewis, J. M., Savage, R. S., Beeching, N. J., Beadsworth, M. B. J., Feasey, N., and Covington, J. A. (2017). Identifying volatile metabolite signatures for the diagnosis of bacterial respiratory tract infection using electronic nose technology: a pilot study. PLOS ONE 12:e0188879. doi: 10.1371/journal.pone.0188879

Li, J., Song, X., Yang, T., Chen, Y., Gong, Y., Yin, X., et al. (2016). A systematic review of antibiotic prescription associated with upper respiratory tract infections in China. Medicine (Baltimore). 95:e3587. doi: 10.1097/MD.0000000000003587

Li, T., Zhu, F., Guo, W., Gu, H., Zhao, J., Yan, M., et al. (2017a). Selective capture and rapid identification of $E$. coli $\mathrm{O} 157: \mathrm{H} 7$ by carbon nanotube multilayer biosensors and microfluidic chip-based LAMP. RSC Adv. 7, 30446-30452. doi: 10.1039/C7RA04583B

Li, Y., Yang, X., and Zhao, W. (2017b). Emerging microtechnologies and automated systems for rapid bacterial identification and antibiotic susceptibility testing. SLAS Technol. 22, 585-608. doi: $10.1177 / 2472630317727519$

Lim, S. H., Mix, S., Xu, Z., Taba, B., Budvytiene, I., Berliner, A. N., et al. (2014). Colorimetric sensor array allows fast detection and simultaneous identification of sepsis-causing bacteria in spiked blood culture. J. Clin. Microbiol. 52, 592-598. doi: 10.1128/JCM.02377-13

Liu, C. Y., Han, Y. Y., Shih, P. H., Lian, W. N., Wang, H. H., Lin, C. H., et al. (2016). Rapid bacterial antibiotic susceptibility test based on simple surfaceenhanced Raman spectroscopic biomarkers. Sci. Rep. 1-15. doi: 10.1038/ srep23375

Liu, T., Lu, Y., Gau, V., Liao, J. C., and Wong, P. K. (2014). Rapid antimicrobial susceptibility testing with electrokinetics enhanced biosensors for diagnosis of acute bacterial infections. Ann. Biomed. Eng. 42. doi: 10.1007/s10439-014-1040-6 
Liu, Z., Banaei, N., and Ren, K. (2017a). Microfluidics for combating antimicrobial resistance. Trends Biotechnol. 35, 1129-1139. doi: 10.1016/j.tibtech.2017.07.008

Liu, Z., Sun, H., and Ren, K. (2017b). A multiplexed, gradient-based, full-hydrogel microfluidic platform for rapid, high-throughput antimicrobial susceptibility testing. ChemPlusChem 82, 792-801. doi: 10.1002/cplu.201600654

London, R., Schwedock, J., Sage, A., Valley, H., Meadows, J., Waddington, M., et al. (2010). An automated system for rapid non-destructive enumeration of growing microbes. PLoS ONE 5:e8609. doi: 10.1371/journal.pone.0008609

Longo, G., Alonso-Sarduy, L., Rio, L. M., Bizzini, A., Trampuz, A., Notz, J., et al. (2013). Rapid detection of bacterial resistance to antibiotics using AFM cantilevers as nanomechanical sensors. Nat. Nanotechnol. 8, 522-526. doi: 10.1038/nnano.2013.120

Lonsdale, C. L., Taba, B., Queralto, N., Lukaszewski, R. A., Martino, R. A., Rhodes, P. A., et al. (2013). The use of colorimetric sensor arrays to discriminate between pathogenic bacteria. PLoS ONE 8:e62726. doi: 10.1371/journal.pone.0062726

López-Marzo, A. M., and Merkoçi, A. (2016). Paper-based sensors and assays: a success of the engineering design and the convergence of knowledge areas. Lab. Chip. 16, 3150-3176. doi: 10.1039/C6LC00737F

Luka, G., Ahmadi, A., Najjaran, H., Alocilja, E., DeRosa, M., Wolthers, K., et al. (2015). Microfluidics integrated biosensors: a leading technology towards lab-on-a-chip and sensing applications. Sensors 15, 30011-30031. doi: $10.3390 / \mathrm{s} 151229783$

Mach, K. E., Mohan, R., Baron, E. J., Shih, M.-C., Gau, V., Wong, P. K., et al. (2011). A biosensor platform for rapid antimicrobial susceptibility testing directly from clinical samples. J. Urol. 185, 148-153. doi: 10.1016/j.juro.2010.09.022

Malmberg, C., Yuen, P., Spaak, J., Cars, O., Tängdén, T., and Lagerbäck, P. (2016). A novel microfluidic assay for rapid phenotypic antibiotic susceptibility testing of bacteria detected in clinical blood cultures. PLoS ONE 11:e0167356. doi: 10.1371/journal.pone. 0167356

Marco, F. (2017). Molecular methods for septicemia diagnosis. Enferm. Infecc. Microbiol. Clin. (English ed.) 35, 586-592. doi: 10.1016/j.eimce.2017.03.023

Marder, E. P., Cieslak, P. R., Cronquist, A. B., Dunn, J., Lathrop, S., RabatskyEhr, T., et al. (2017). Incidence and trends of infections with pathogens transmitted commonly through food and the effect of increasing use of cultureindependent diagnostic tests on surveillance - foodborne diseases active surveillance network, 10 U.S. Sites, 2013-2016. MMWR. Morb. Mortal. Wkly. Rep. 66, 397-403. doi: 10.15585/mmwr.mm6615al

Marschal, M., Bachmaier, J., Autenrieth, I., Oberhettinger, P., Willmann, M., and Petera, S. (2017). Evaluation of the accelerate pheno system for fast identification and antimicrobial susceptibility testing from positive blood cultures in bloodstream infections caused by gram-negative pathogens. J. Clin. Microbiol. 55, 2116-2126. doi: 10.1128/JCM.00181-17

Mashalla, Y., Setlhare, V., Massele, A., Sepako, E., Tiroyakgosi, C., Kgatlwane, J., et al. (2017). Assessment of prescribing practices at the primary healthcare facilities in botswana with an emphasis on antibiotics: findings and implications. Int. J. Clin. Pract. 71:e13042. doi: 10.1111/ijcp.13042

Matsumoto, Y., Sakakihara, S., Grushnikov, A., Kikuchi, K., Noji, H., Yamaguchi, A., et al. (2016). A microfluidic channel method for rapid drugsusceptibility testing of pseudomonas aeruginosa. PLOS ONE 11:e0148797. doi: 10.1371/journal.pone.0148797

Maugeri, G., Lychko, I., Sobral, R., and Roque, A. C. A. (2019). Identification and antibiotic-susceptibility profiling of infectious bacterial agents: a review of current and future trends. Biotechnol. J. 14:e1700750. doi: 10.1002/biot.201700750

Maurer, F. P., Christner, M., Hentschke, M., and Rohde, H. (2017). Advances in rapid identification and susceptibility testing of bacteria in the clinical microbiology laboratory: implications for patient care and antimicrobial stewardship programs. Infect. Dis. Rep. 9:6839. doi: 10.4081/idr.2017.6839

Mauri, C., Principe, L., Bracco, S., Meroni, E., Corbo, N., Pini, B., et al. (2017). Identification by mass spectrometry and automated susceptibility testing from positive bottles: a simple, rapid, and standardized approach to reduce the turnaround time in the management of blood cultures. BMC Infect. Dis. 17, 1-8. doi: 10.1186/s12879-017-2851-5

Maxson, T., Taylor-Howell, C. L., and Minogue, T. D. (2017). Semi-quantitative MALDI-TOF for antimicrobial susceptibility testing in staphylococcus aureus. PLoS ONE 12:e0183899. doi: 10.1371/journal.pone.0183899
McAdam, A. J. (2017). Unforeseen consequences: culture-independent diagnostic tests and epidemiologic tracking of foodborne pathogens. J. Clin. Microbiol. 55, 1978-1979. doi: 10.1128/JCM.00678-17

Mecklenburg, M., Chen, Q., Andersson, A., and Xie, B. (2017). A biosensing strategy for fast profiling of antibiotic resistance. Proc. Technol. 27, 33-34. doi: 10.1016/j.protcy.2017.04.016

Metzger, S., Frobel, R. A., and Dunne, W. M. (2014). Rapid simultaneous identification and quantitation of staphylococcus aureus and Pseudomonas aeruginosa directly from bronchoalveolar lavage specimens using automated microscopy. Diagn. Microbiol. Infect. Dis. 79, 160-165. doi: 10.1016/j.diagmicrobio.2013.11.029

Mezger, A., Gullberg, E., Göransson, J., Zorzet, A., Herthnek, D., Tano, E., et al. (2015). A general method for rapid determination of antibiotic susceptibility and species in bacterial infections. J. Clin. Microbiol. 53, 425-432. doi: 10.1128/JCM.02434-14

Miller, J. M., Binnicker, M. J., Campbell, S., Carroll, K. C., Chapin, K. C., Gilligan, P. H., et al. (2018). A guide to utilization of the microbiology laboratory for diagnosis of infectious diseases: 2018 update by the infectious diseases society of America and the American society for microbiologya. Clin. Infect. Dis. 67, e1-e94. doi: 10.1093/cid/ciy381

Mohan, R., Mach, K. E., Bercovici, M., Pan, Y., Dhulipala, L., Wong, P. K., et al. (2011). Clinical validation of integrated nucleic acid and protein detection on an electrochemical biosensor array for urinary tract infection diagnosis. PLoS ONE 6:e26846. doi: 10.1371/journal.pone.0026846

Montgomery, S., Roman, K., Ngyuen, L., Cardenas, A. M., Knox, J., Tomaras, A. P., et al. (2017). Prospective evaluation of light scatter technology paired with matrix-assisted laser desorption ionization-time of flight mass spectrometry for rapid diagnosis of urinary tract infections downloaded from. J. Clin. Microbiol. 55, 1802-1811. doi: 10.1128/JCM.00027-17

Nazemi, E., Hassen, W. M., Frost, E. H., and Dubowski, J. J. (2017). Monitoring growth and antibiotic susceptibility of Escherichia coli with photoluminescence of GaAs/AlGaAs quantum well microstructures. Biosens. Bioelectron. 93, 234-240. doi: 10.1016/j.bios.2016.08.112

Nijhuis, R. H. T., Guerendiain, D., Claas, E. C. J., and Templeton, K. E. (2017). Comparison of ePlex respiratory pathogen panel with laboratory-developed real-time PCR assays for detection of respiratory pathogens. J. Clin. Microbiol. 55, 1938-1945. doi: 10.1128/JCM.00221-17

Noncommercial culture and drug-susceptibility testing methods for screening patients at risk for multidrug-resistant tuberculosis: policy statement (2011). World Health Organization. Available online at: http://www.ncbi.nlm.nih.gov/ pubmed/23586116 (accessed March 13, 2019).

Notomi, T., Okayama, H., Masubuchi, H., Yonekawa, T., Watanabe, K., Amino, N., et al. (2000). Loop-mediated isothermal amplification of DNA. Nucleic Acids Res. 28:E63. Available online at: http://www.ncbi.nlm. nih.gov/pubmed/10871386 (accessed March 7, 2019). doi: 10.1093/nar/28. 12.e63

Oblath, E. A., Henley, W. H., Alarie, J. P., and Ramsey, J. M. (2013). A microfluidic chip integrating DNA extraction and real-time PCR for the detection of bacteria in saliva. Lab. Chip. 13, 1325-1332. doi: 10.1039/c3lc40961a

Patel, T. S., Kaakeh, R., Nagel, J. L., Newton, D. W., and Stevenson, J. G. (2017). Cost analysis of implementing matrix- assisted laser desorption ionization-time of flight mass spectrometry plus real-time antimicrobial stewardship intervention for bloodstream infections. J. Clin. Microbiol. 55, 60-67. doi: 10.1128/JCM.01452-16

Perry-O'Keefe, H., Stender, H., Broomer, A., Oliveira, K., Coull, J., and HyldigNielsen, J. J. (2001). Filter-based PNA in situ hybridization for rapid detection, identification and enumeration of specific micro-organisms. J. Appl. Microbiol. 90, 180-9. doi: 10.1046/j.1365-2672.2001.01230.x

Persaud, K., and Dodd, G. (1982). Analysis of discrimination mechanisms in the mammalian olfactory system using a model nose. Nature 299, 352-355. doi: 10.1038/299352a0

Peytavi, R. (2005). Microfluidic device for rapid (andlt;15 min) automated microarray hybridization. Clin. Chem. 51, 1836-1844. doi: 10.1373/clinchem.2005.052845

Plüddemann, A., Onakpoya, I., Harrison, S., Shinkins, B., Tompson, A., Davis, R., et al. (2015). "Position paper on anti-microbial resistance diagnostics," in Centre for Evidence-Based Medicine. 1-142. doi: 10.13140/RG.2.1.1135.9846 
Priye, A., Bird, S. W., Light, Y. K., Ball, C. S., Negrete, O. A., and Meagher, R. J. (2017). A smartphone-based diagnostic platform for rapid detection of Zika, chikungunya and dengue viruses. Sci. Rep. 7:44778. doi: 10.1038/srep 44778

Pulido, M. R., García-Quintanilla, M., Martín-Peña, R., Cisneros, J. M., and McConnell, M. J. (2013). Progress on the development of rapid methods for antimicrobial susceptibility testing. J. Antimicrob. Chemother. 68, 2710-2717. doi: $10.1093 / \mathrm{jac} / \mathrm{dkt} 253$

Quainoo, S., Coolen, J. P. M., van Hijum, S. A. F. T., Huynen, M. A., Melchers, W. J. G., van Schaik, W., et al. (2017). Whole-genome sequencing of bacterial pathogens: the future of nosocomial outbreak analysis. Clin. Microbiol. Rev. 30, 1015-1063. doi: 10.1128/CMR.00016-17

Sahoo, P. R., Sethy, K., Mohapatra, S., and Panda, D. (2016). Loop mediated isothermal amplification: an innovative gene amplification technique for animal diseases. Vet. World 9, 465-469. doi: 10.14202/vetworld.2016. 465-469

Salimnia, H., Fairfax, M. R., Lephart, P., Morgan, M., Gilbreath, J. J., Butler-Wu, S. M., et al. (2014). An international, prospective, multicenter evaluation of the combination of advanDx staphylococcus QuickFISH BC with mecA XpressFISH for detection of methicillinresistant staphylococcus aureus isolates from positive blood cultures. J. Clin. Microbiol. 52, 3928-32. doi: 10.1128/JCM.01 811-14

Sanbonmatsu-Gámez, S., Pérez-Ruiz, M., Lara-Oya, A., PedrosaCorral, I., Riazzo-Damas, C., and Navarro-Marí, J. M. (2015). Analytical performance of the automated multianalyte point-ofcare mariPOC $\AA$ for the detection of respiratory viruses. Diagn Micr Infec Dis. 83, 252-256. doi: 10.1016/j.diagmicrobio.2015. 07.010

Saviauk, T., Kiiski, J. P., Nieminen, M. K., Tamminen, N. N., Roine, A. N., Kumpulainen, P. S., et al. (2018). Electronic nose in the detection of wound infection bacteria from bacterial cultures: a proof-of-principle study. Eur. Surg. Res. 59, 1-11. doi: 10.1159/000485461

Schoepp, N. G., Liaw, E. J., Winnett, A., WinnettSavela, E. S., Garner, O. B., and Ismagilov, R. F. (2020). Differential DNA accessibility to polymerase enables 30-minute phenotypic-lactam antibiotic susceptibility testing of carbapenem-resistant Enterobacteriaceae. PLoS Biology. 18. doi: 10.1371/journal.pbio.3000652

Schoepp, N. G., Schlappi, T. S., Curtis, M. S., Butkovich, S. S., Miller, S., Humphries, R. M., et al. (2017). Rapid pathogen-specific phenotypic antibiotic susceptibility testing using digital LAMP quantification in clinical samples. Sci. Transl. Med. 9:eaal3693. doi: 10.1126/scitranslmed.aal3693

Schumacher, A., Vranken, T., Malhotra, A., Arts, J. J. C., and Habibovic, P. (2018). In vitro antimicrobial susceptibility testing methods: agar dilution to 3D tissue-engineered models. Eur. J. Clin. Microbiol. Infect. Dis. 37, 187-208. doi: 10.1007/s10096-017-3089-2

Sharp, S. (2020). Specific Reveal ${ }^{\mathrm{TM}}-$ Specific Technologies. Specif. Reveal. AST Hours not Days. Available online at: https://www.specific-dx.com/reveal-ast (accessed May 17, 2020).

She, R. C., and Bender, J. M. (2019). Advances in rapid molecular blood culture diagnostics: healthcare impact, laboratory implications, and multiplex technologies. J. Appl. Lab. Med. 3, 617-630. doi: 10.1373/jalm.2018. 027409

Shi, X., Kadiyala, U., Vanepps, J. S., and Yau, S. T. (2018). Culture-free bacterial detection and identification from blood with rapid, phenotypic, antibiotic susceptibility testing. Sci. Rep. 8:3416.

Spanu, T., Fiori, B., D’Inzeo, T., Canu, G., Campoli, S., Giani, T., et al. (2012). Evaluation of the new NucliSENS EasyQ KPC Test for rapid detection of klebsiella pneumoniae carbapenemase genes (blaKPC). J. Clin. Microbiol. 50, 2783-2785. doi: 10.1128/JCM.00284-12

Sparbier, K., Schubert, S., and Kostrzewa, M. (2016). MBT-ASTRA: a suitable tool for fast antibiotic susceptibility testing? Methods. 104, 48-54. doi: 10.1016/j.ymeth.2016.01.008

Strålin, K., Ehn, F., Giske, C. G., Ullberg, M., Hedlund, J., Petersson, J., et al. (2016). The IRIDICA PCR/electrospray ionization-mass spectrometry assay on bronchoalveolar lavage for bacterial etiology in mechanically ventilated patients with suspected pneumonia. PLOS ONE 11:e0159694. doi: 10.1371/journal.pone.0159694
Sun, H., Liu, Z., Hu, C., and Ren, K. (2016). Cell-on-hydrogel platform made of agar and alginate for rapid, low-cost, multidimensional test of antimicrobial susceptibility. Lab. Chip. 16, 3130-3138. doi: 10.1039/C6LC0 0417B

Syal, K., Iriya, R., Yang, Y., Yu, H., Wang, S., Haydel, S. E., et al. (2016). Antimicrobial susceptibility test with plasmonic imaging and tracking of single bacterial motions on nanometer scale. ACS Nano 10, 845-852. doi: 10.1021/acsnano.5b05944

Syal, K., Mo, M., Yu, H., Iriya, R., Jing, W., Guodong, S., et al. (2017). Current and emerging techniques for antibiotic susceptibility tests. Theranostics 7 , 1795-1805. doi: 10.7150/thno.19217

Tao, N., and Syal, K. (2016). US 2017/0045514 A1. Antibiotic Susceptibility Testing via Plasmonic Imaging and Tracking.

Trienski, T. L., Barrett, H. L., Pasquale, T. R., DiPersio, J. R., and File, T. M. (2013). Evaluation and use of a rapid Staphylococcus aureus assay by an antimicrobial stewardship program. Am. J. Heal. Pharm. 70, 1908-1912. doi: 10.2146/ajhp130118

United nations meeting on antimicrobial resistance (2016). Bull. World Health Organ. 94, 638-639. doi: 10.2471/BLT.16.020916

Vakkila, J., Koskinen, J. O., Brandt, A., Muotiala, A., Liukko, V., Soittu, S., et al. (2015). Detection of group a streptococcus from pharyngeal swab samples by bacterial culture is challenged by a novel mariPOC point-of-care test. J. Clin. Microbiol. 53, 2079-2083. doi: 10.1128/JCM.00018-15

van Belkum, A., Bachmann, T. T., Lüdke, G., Lisby, J. G., Kahlmeter, G., Mohess, A., et al. (2019a). Developmental roadmap for antimicrobial susceptibility testing systems. Nat. Rev. Microbiol. 17, 51-62. doi: 10.1038/s41579-0180098-9

van Belkum, A., Bachmann, T. T., Lüdke, G., Lisby, J. G., Kahlmeter, G., Mohess, A., et al. (2019b). Developmental roadmap for antimicrobial susceptibility testing systems. Nat. Rev. Microbiol. 17, 51-62.

van Belkum, A., and Rochas, O. (2018). Laboratory-based and point-of-care testing for MSSA/MRSA detection in the age of whole genome sequencing. Front. Microbiol. 9:1437. doi: 10.3389/fmicb.2018.01437

Verma, J., Saxena, S., and Babu, S. G. (2013). ELISA-Based Identification and Detection of Microbes. (Springer, Berlin, Heidelberg), 169-186. doi: 10.1007/978-3-642-34410-7_13

Veses-Garcia, M., Antypas, H., Löffler, S., Brauner, A., Andersson-Svahn, H., and Richter-Dahlfors, A. (2018). Rapid phenotypic antibiotic susceptibility testing of uropathogens using optical signal analysis on the nanowell slide. Front. Microbiol. 9:1530. doi: 10.3389/fmicb.2018.01530

von Ah, U., Wirz, D., and Daniels, A. U. (2009). Isothermal micro calorimetry-a new method for MIC determinations: results for 12 antibiotics and reference strains of E. coli and S. aureus. BMC Microbiol. 9:106. doi: 10.1186/1471-2180-9-106

Vrioni, G., Tsiamis, C., Oikonomidis, G., Theodoridou, K., Kapsimali, V., and Tsakris, A. (2018). MALDI-TOF mass spectrometry technology for detecting biomarkers of antimicrobial resistance: current achievements and future perspectives. Ann. Transl. Med. 6, 240-240. doi: 10.21037/atm.20 18.06.28

Walker, G. T., Fraiser, M. S., Schram, J. L., Little, M. C., Nadeau, J. G., and Malinowski, D. P. (1992). Strand displacement amplification-an isothermal, in vitro DNA amplification technique. Nucleic Acids Res. 20, 1691-6. Available online at: http://www.ncbi.nlm.nih.gov/pubmed/1579461 (accessed March 7, 2019). doi: $10.1093 /$ nar/20.7.1691

Wang, L.-J., Naudé, N., Demissie, M., Crivaro, A., Kamoun, M., Wang, P., et al. (2018). Analytical validation of an ultra low-cost mobile phone microplate reader for infectious disease testing. Clin. Chim. Acta 482, 21-26. doi: $10.1016 /$ j.cca.2018.03.013

Weibull, E., Antypas, H., Kjäll, P., Brauner, A., Andersson-Svahn, H., and Richter-Dahlfors, A. (2014). Bacterial nanoscale cultures for phenotypic multiplexed antibiotic susceptibility testing. J. Clin. Microbiol. 52, 3310-3317. doi: 10.1128/JCM.01161-14

Wieser, A., Schneider, L., Jung, J., and Schubert, S. (2012). MALDI-TOF MS in microbiological diagnostics-identification of microorganisms and beyond (mini review). Appl. Microbiol. Biotechnol. 93, 965-974. doi: 10.1007/s00253-011-3783-4

Yamada, K., Wanchun, J., Ohkura, T., Murai, A., Hayakawa, R., Kinoshita, K., et al. (2013). Detection of methicillin-resistant staphylococcus aureus using 
a specific Anti-PBP2a chicken IgY antibody. Jpn. J. Infect. Dis. 66, 103-108. doi: 10.7883/yoken.66.103

Yang, R., Zhang, H., Li, X., Ye, L., Gong, M., Yang, J., et al. (2018). A multiplex loopmediated isothermal amplification assay for rapid screening of Acinetobacter baumannii and D carbapenemase OXA-23 gene. Biosci. Rep. 38:BSR20180425. doi: 10.1042/BSR20180425

Yi, Q., Cai, D., Xiao, M., Nie, M., Cui, Q., Cheng, J., et al. (2019). Direct antimicrobial susceptibility testing of bloodstream infection on SlipChip. Biosens. Bioelectron. 135, 200-207. doi: 10.1016/j.bios.2019. 04.003

Zhu, K., Dietrich, R., Didier, A., Doyscher, D., and Märtlbauer, E. (2014). Recent developments in antibody-based assays for the detection of bacterial toxins. Toxins (Basel). 6, 1325-1348. doi: 10.3390/toxins6041325
Conflict of Interest: VH was employed by Fimlab Laboratories.

The remaining authors declare that the research was conducted in the absence of any commercial or financial relationships that could be construed as a potential conflict of interest.

Copyright (c) 2020 Vasala, Hytönen and Laitinen. This is an open-access article distributed under the terms of the Creative Commons Attribution License (CC BY). The use, distribution or reproduction in other forums is permitted, provided the original author(s) and the copyright owner(s) are credited and that the original publication in this journal is cited, in accordance with accepted academic practice. No use, distribution or reproduction is permitted which does not comply with these terms. 